
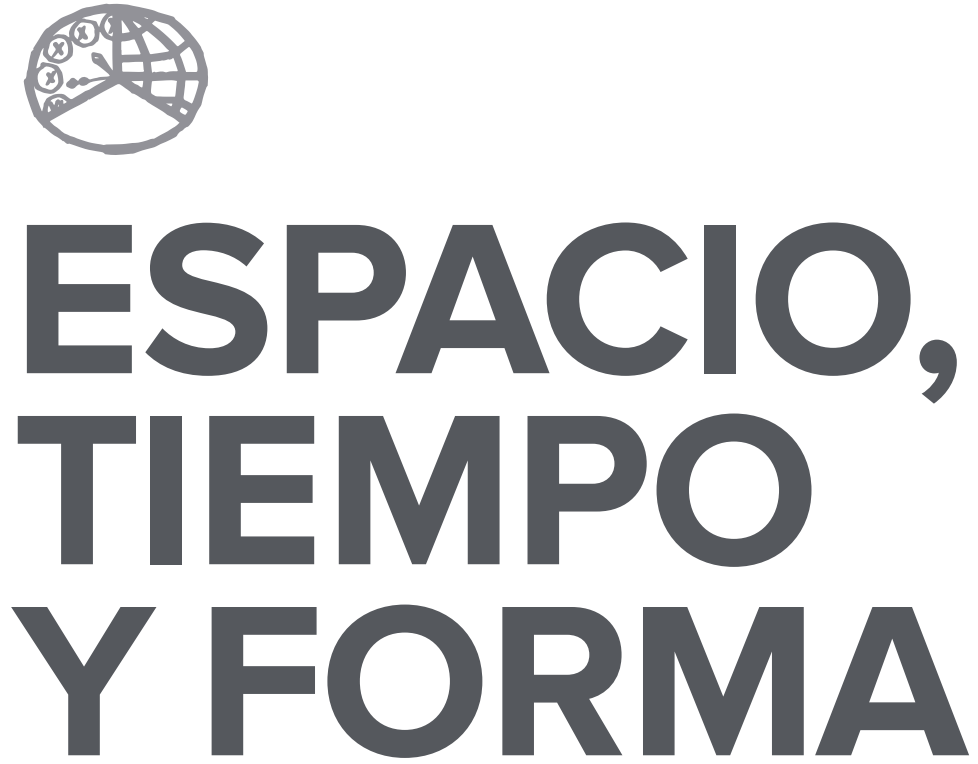

AÑO 2017

ISSN 0214-9745

E-ISSN 2340-1362

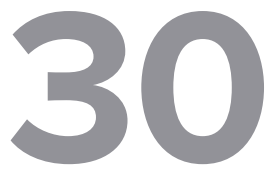

SERIE III HISTORIA MEDIEVAL

REVISTA DE LA FACULTAD DE GEOGRAFÍA E HISTORIA 


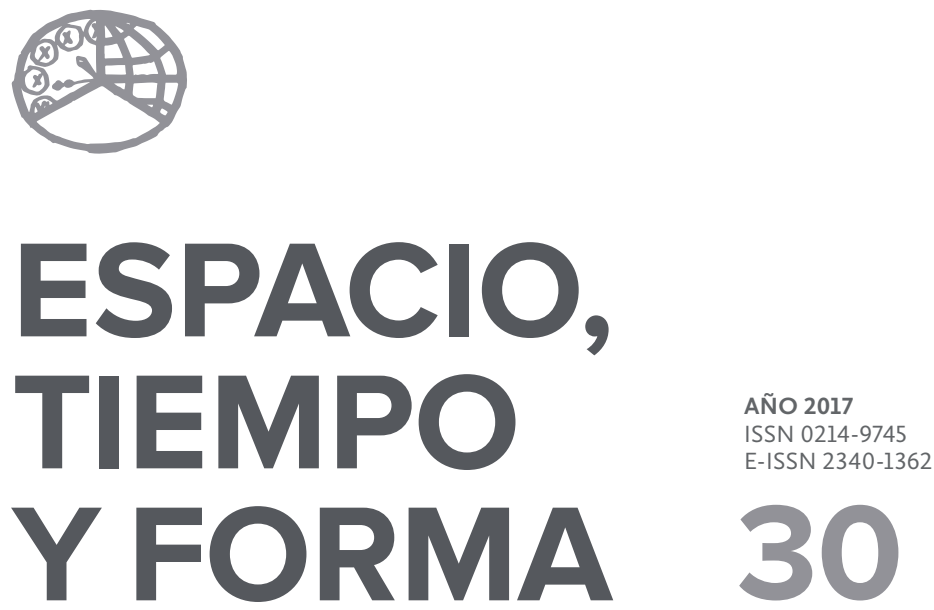

SERIE III HISTORIA MEDIEVAL

REVISTA DE LA FACULTAD DE GEOGRAFÍA E HISTORIA

http://dx.doi.org/10.5944/etfiii.30.2017

\section{UกED}

UNIVERSIDAD NACIONAL DE EDUCACIÓN A DISTANCIA 
La revista Espacio, Tiempo y Forma (siglas recomendadas: ETF),

de la Facultad de Geografía e Historia de la UNED, que inició su publicación el año 1988, está organizada de la siguiente forma:

$$
\begin{aligned}
& \text { SERIE I - Prehistoria y Arqueología } \\
& \text { SERIE II - Historia Antigua } \\
& \text { SERIE III - Historia Medieval } \\
& \text { SERIE IV - Historia Moderna } \\
& \text { SERIE V - Historia Contemporánea } \\
& \text { SERIE VI - Geografía } \\
& \text { SERIE VII - Historia del Arte }
\end{aligned}
$$

Excepcionalmente, algunos volúmenes del año 1988 atienden a la siguiente numeración:
N. ${ }^{\circ} 1 \quad-$ Historia Contemporánea
N. ${ }^{\circ} 2-$ Historia del Arte
N. ${ }^{\circ} 3-$ Geografía
N. ${ }^{\circ} 4 \quad-$ Historia Moderna

ETF no se solidariza necesariamente con las opiniones expresadas por los autores.

UNIVERSIDAD NACIONAL DE EDUCACIÓN A DISTANCIA

Madrid, 2017

SERIE III - HISTORIA MEDIEVAL N. ${ }^{\circ} 30,2017$

ISSN 0214-9745 $\cdot$ E-ISSN 2340-1362

DEPÓSITO LEGAL M-21037-1988

URL: ETF III - HISTORIA MEDIEVAL · http://revistas.uned.es/indeX.php/ETFIII

DISEÑO Y COMPOSICIÓN

Carmen Chincoa Gallardo · http://www.laurisilva.net/cch

Impreso en España $\cdot$ Printed in Spain 


\section{ARTÍCULOS}





\title{
EL CABILDO CATEDRALICIO DE \\ MALLORCA Y LA POLIITICA DE \\ FERNANDO II EL CATÓLICO
}

\section{THE CATHEDRAL CHAPTER OF \\ MAJORCA AND THE POLITICS OF FERNANDO II THE CATHOLIC}

\author{
Albert Cassanyes Roig \\ Recepción: 2017/1/11 . Comunicación de observaciones de evaluadores: 2017/2/14 . \\ Aceptación: 2017/2/21 \\ DOI: http://dx.doi.org/10.5944/etfiii.30.2017.17889
}

\section{Resumen ${ }^{2}$}

Fernando Il e Isabel de Castilla obtuvieron el título de «Reyes Católicos» gracias a su política religiosa. El presente artículo estudia las relaciones entre el Cabildo de Mallorca y el rey católico, con el objetivo de analizar la respuesta de la institución canonical a la política real. A tal efecto, se han revisado los libros de actas capitulares. Las cuestiones económicas fueron una de las principales causas que motivaron el envío de embajadas al rey. También hubo un cierto enfrentamiento por la instauración de la Inquisición, mientras el Cabildo colaboró con las campañas norteafricanas del monarca. En el campo de la cultura, representada por el lulismo, Fernando Il no encontró un apoyo significativo del Cabildo, aunque sí de algunos canónigos en particular. Finalmente, el colegio canonical también realizó las exequias acostumbradas a los miembros de la familia real. Todo ello presenta un Cabildo complaciente que no se enfrentó abiertamente al monarca.

\section{Palabras clave}

Canónigos; embajadas; Fernando II el Católico; Inquisición; Mallorca; política religiosa.

1. Investigador predoctoral en formación, Universitat de Lleida. C.e.: albert.cassanyes@historia.udl.cat

2. La elaboración del presente artículo se inscribe en el proyecto «Expresividad, sentimiento y emoción (siglos XII-XV)» (HAR2016-75028-P) y ha contado con el apoyo de la Secretaria d'Universitats i Recerca del Departament d'Economia i Coneixement de la Generalitat de Catalunya. 


\begin{abstract}
Fernando II and Isabel of Castile obtained the title of «Catholic Monarchs» thanks to their religious policies. This paper considers the relationship between the chapter of Majorca and the Catholic king, with the aim of analysing the response of the canonry to royal politics. For this purpose, the books of the chapter proceedings have been examined. Economic issues were one of the main reasons for sending embassies to the king. Furthermore, there was a confrontation over the introduction of the Inquisition, while at the same time the chapter cooperated during the North African campaigns of the king. In the cultural sphere, dominated by Lullism, Fernando II did not find significant support from the chapter, with the exception of a few individual canons. Lastly, the canons participated in the customary funeral rites for the royal family. On the whole, the conclusion drawn is one of a complaisant chapter that never openly confronted the monarch.
\end{abstract}

\title{
Keywords
}

Canons; Embassies; Fernando II the Catholic; Inquisition; Majorca; Religious Politics. 
EN 1479, tras la muerte de Juan Il de Aragón, su hijo fue coronado con el nombre de Fernando Il. De este modo, pasaba a gobernar también los territorios peninsulares, pues desde I468 ya era rey de Sicilia. Por otro lado, en I469 Fernando de Aragón había contraído matrimonio con Isabel de Castilla. En consecuencia, reinó en la vecina área castellana como consorte desde I475, a pesar de la necesidad de imponerse ante los partidarios de Juana la Beltraneja en una guerra civil que duró hasta $1479{ }^{3}$. Fernando Il de Aragón e Isabel de Castilla obtuvieron el título de «Reyes Católicos» en reconocimiento a sus acciones a favor de la expansión de la Iglesia y del catolicismo. El papa Inocencio VIII fue el primero que concedió dicha titulación a los reyes de Aragón y Castilla en ocasión de la conquista de Granada en $\mathrm{I}_{492}{ }^{4}$. Cuatro años más tarde, en I496, su sucesor Alejandro VI impuso de nuevo este mismo reconocimiento mediante la bula Si convenit, expedida el ig de diciembre de ese año ${ }^{5}$. Entre los distintos méritos que se indicaban para justificar aquella concesión se alegaban la toma de Granada y la finalización de la «Reconquista», los esfuerzos dedicados a la promoción de una cruzada contra el Turco, la expulsión de los judíos en 1492 y la liberación del Reino de Nápoles -que había sido ocupado por las tropas francesas de Carlos VIll de Francia y recobrado por Fernando II de Nápoles con la ayuda del Gran Capitán-. Son, todos ellos, motivos políticos e institucionales que supusieron la prestación de un gran servicio a la cristiandad. De hecho, el Colegio Cardenalicio dio su apoyo a la concesión del título honorífico a los reyes de Castilla y Aragón ${ }^{6}$.

Como parte integrante de la Corona de Aragón, el Reino de Mallorca también estuvo bajo el gobierno de Fernando Il $^{7}$. Sin embargo, el rey no visitó nunca la isla, que constituía uno de los territorios marginales de la monarquía, y más teniendo presente el mayor peso de Castilla y la frecuente estancia del monarca en los territorios castellanos, centro político y espiritual de la unión dinástica ${ }^{8}$. A pesar de ello, Mallorca fue una base fundamental para las campañas norteafricanas del

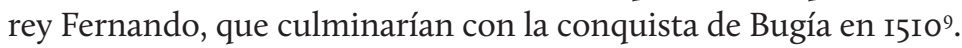

No hay ninguna duda del interés de Fernando Il en promover y difundir la Iglesia en sus territorios, además de apoyar su expansión en el Mediterráneo -frontera

3. Abunda la bibliografía sobre este conflicto. Véase, a modo de ejemplo, SuÁREZ Fernández, Luis: Los Reyes Católicos. La conquista del trono. Madrid, Rialp, 1989, o el capítulo a ese dedicado en EDWARDs, John: La España de los Reyes Católicos. Madrid, Crítica, 2001, pp. 13-47. Asimismo, es una guerra tratada en todas las biografías sobre la reina Isabel, como San Miguel Pérez, Enrique: Isabel I de Castilla. 1474-1504. Burgos, La Olmeda, 1998, o Fernández Álvarez, Manuel: Isabel la Católica. Madrid, Espasa Calpe, 2003, para citar algunas.

4. Véase, en referencia a este hito del reinado de los Reyes Católicos, LADERo QueSADA, Miguel Ángel: La Guerra de Granada (1482-1491). Granada, Diputación Provincial de Granada, 2001.

5. Archivo General de Simancas (AGS), Patronato Real, leg. 38, doc. 14. Publicada en REY, Eusebio: «La bula de Alejandro VI otorgando el título de 'Católicos' a Fernando e Isabel», Razón y Fe, 146 (1952), pp. 59-75.

6. Dumont, Jean: La «incomparable» Isabel la Católica. Madrid, Encuentro, 1993, pp. 215-217.

7. Véase el clásico artículo contextual de SANTAMARía ARÁNDEZ, Álvaro: «Mallorca, al advenir Fernando el Católico», Mayurqa, 2 (1969), pp. 19-47.

8. Fernández Álvarez, Manuel: op. cit. pp. 539-540.

9. Casasnovas CAmps, Miquel Àngel: Història de les Illes Balears. Palma, Editorial Moll, 1998, pp. 218-219. 
más o menos evidente entre el cristianismo y el islam, a pesar del avance turco por el este-, ni del importante papel que, en esta política mediterránea, jugaba la isla de Mallorca. Por otro lado, una de las características del reinado de los Reyes Católicos fue el acrecentamiento de la autoridad real ${ }^{\mathrm{Io}}$. La monarquía fue apropiándose cada vez más de prerrogativas hasta entonces ejercidas por otras instituciones, al mismo tiempo que buscaba influir en aquellas que no lograba controlar directamente. Como no podía ser de otra manera, la participación activa en el ámbito de la religión también fue del interés de los monarcas, que desarrollaron una intensa política religiosa en varios aspectos. Esto obligó a mantener unas relaciones bastante fluidas con los obispos y, en menor medida, con los cabildos catedralicios de sus territorios. El Cabildo de Mallorca no quedó al margen de la política de Fernando II, aunque no se tratara, ni por asomo, de uno de los más destacados de los reinos hispanos.

Ante este punto de partida, el presente artículo quiere ahondar en las relaciones habidas entre el Cabildo catedralicio de Mallorca y el rey Fernando II a nivel político, económico y religioso ${ }^{\mathrm{II}}$. De hecho, el estudio de las acciones del Cabildo en este período es fundamental, pues se trata de una etapa protagonizada por obispos ausentes, esto es prelados que no residían en sus diócesis. Por este motivo, el gobierno de la demarcación estaba en manos de los vicarios generales, que regían el obispado juntamente a los canónigos que conformaban el Cabildo. En otras palabras, se trata de uno de los momentos en que la institución canonical gozaba de un mayor poder. El objetivo final de este artículo es, pues, aportar una primera visión de la acción del Cabildo catedralicio frente a las medidas tomadas por la monarquía católica, así como su respuesta a la reforma religiosa que los reyes iban imponiendo.

\section{LAS RELACIONES ENTRE EL CABILDO Y EL REY}

Como se ha indicado anteriormente, Fernando Il mantenía un cierto contacto con los canónigos de Mallorca, aunque su relación distara mucho de ser constante. La forma de comunicación ordinaria era el intercambio epistolar. Sin embargo, en la mayoría de ocasiones, las órdenes del rey eran enviadas al lugarteniente general de Mallorca, que luego se encargaba de transmitirlas al Cabildo. A pesar de ello, el monarca también podía mandar las cartas directamente a la institución canonical. La correspondencia era abierta y leída en sesión capitular; a veces se

10. Sobre la organización política de la monarquía de los Reyes Católicos -especialmente, Castilla-, véase Fernández Álvarez, Manuel: op. cit. pp. 533-560.

11. Una nómina de los canónigos mallorquines durante el reinado de Fernando Il ha sido establecida en CASSANYES RoIG, Albert: «La provisión de canonicatos y obispados en Mallorca durante el reinado de Fernando II el Católico (1479-1516)», en trámite de publicación. 
transcribía su contenido en el acta correspondiente ${ }^{\mathrm{I2}}$. Por su parte, el Cabildo también podía enviar una carta al monarca si lo consideraba conveniente. Así se hizo el 22 de agosto de I5I5, cuando los canónigos eligieron al sochantre Llorenç de Santacília y a los canónigos Francesc Net y Arnau Albertí para que redactaran el documento que debería remitirse al rey ${ }^{13}$.

En otras ocasiones, pero, el Cabildo podía considerar más efectiva la remesa de embajadas a la corte, un recurso que fue utilizado con mucha frecuencia por los canónigos. Por ejemplo, en I483 el Cabildo decidió mandar a Pere Vicens ante el rey para que consiguiera del monarca una gracia referente a los diezmos. Para preparar aquella expedición, se formó una comisión, integrada por el arcediano Pere Gual, el deán Bartomeu Sureda y los canónigos Gaspar Albertí y Miquel López, que trabajó juntamente a los representantes elegidos por el obispo Diego de Avellaneda ${ }^{14}$. Poco más tarde, en enero de I489, el Cabildo decidió enviar el sacrista Arnau de Santacília como embajador ante el rey -al mismo tiempo que mandaba el canónigo de Barcelona Jeroni Pau y el mallorquín Esperandéu Espanyol a Roma, donde este último ya se encontraba- para defender las libertades y las inmunidades eclesiásticas ${ }^{15}$. Uno de los temas más conflictivos en lo que se refería a estas libertades era la controversia generada por el pago de dos sueldos por libra que todos los mallorquines, incluidos los eclesiásticos, tenían que abonar durante diez años para contribuir a la amortización de los intereses de la deuda (censales) que pesaban sobre la Universidad de Mallorca. Este pago había sido dispuesto por el rey mediante la Pragmática de Granada el 26 de agosto de I499, por la cual reorganizaba la recaudación tributaria y suspendía durante diez años la exención de la que gozaban los grupos privilegiados ${ }^{16}$. El I7 de febrero de 1500 se formó una comisión de seis personas ${ }^{17}$ para que eligiera un síndico para mandar a la corte real y conseguir una gracia de exención referente a aquel pago. Francesc

\footnotetext{
12. Por ejemplo, en Arxiu Capitular de Mallorca (ACM), Actas Capitulares, 01-10-ACA-019, f. 169v.

13. ACM, Actas Capitulares, 01-10-ACA-019, f. 215r.

14. ACM, Actas Capitulares, 01-10-ACA-016, f. $104 \mathrm{~V}$.

15. ACM, Actas Capitulares, 01-10-ACA-016, f. 175v. La defensa de las libertades y de las inmunidades eclesiásticas fue una cuestión de constante preocupación para los canónigos. El 11 de marzo de 1511 se eligieron cinco clérigos encargados de su defensa: el guardián de los monasterios franciscanos de Mallorca, el profesor de Teología Antoni Jaume, los hebdomadarios de la catedral Gabriel Vaquer y Miquel Garcia, y el presbítero Tomàs Castelló. A estos se añadieron los canónigos Jaume Armadans -sustituido por Miquel Gual tras su muerte, acaecida en verano de 1511 (ACM, Actas Capitulares, 01-10-ACA-019, f. 48v)-y Antoni Joan Busquets. ACM, Actas Capitulares, 01-10-ACA-019, ff. $13 \mathrm{~V}$ y $14 \mathrm{r}$.

16. Santamaría ArÁndez, Álvaro: «Pragmática de Granada, una década de la historia de Mallorca (1495-1504)», Boletín de la Cámara Oficial de Comercio, Industria y Navegación de Palma de Mallorca, 670-671 (1971), pp. 3-73; JUAN VIDAL, Josep: «Mallorca en la segunda mitad del siglo XV. Panorama socioeconómico», Medicina Balear, 22/extra 1 (2007), p. 27. En 1405 se firmó en Mallorca el Contracte Sant, un convenio entre la Universidad de Mallorca y los acreedores censalistas. De acuerdo con este, la Universidad quedaba obligada a dedicar la totalidad de sus ingresos a la amortización de la deuda pública y de los intereses de ella derivada. Los fondos fueron gestionados por la Universal Consignación, integrada por representantes de los acreedores. Para esta cuestión, véanse URGELL HERNÁNDEZ, Ricard: «Dinàmica del deute públic a la Universitat de Mallorca en el segle XV», en SÁnchez Martínez, Manuel, Furió i Diego, Antoni y Bertran i Rolgé, Prim (coords.). Col/loqui Corona, municipis i fiscalitat a la Baixa Edat Mitjana. Lérida, Institut d'Estudis llerdencs, 1997, pp. 675-701; CATEURA Bennàsser, Pau: L'administració atrapada. Crèdit, finances i adaptacions fiscals en el Regne de Mallorca (segle XV). Palma, El Tall, 2008.

17. Integraron dicha comisión los canónigos Gaspar Albertí y Esperandéu Espanyol, el prior de los dominicos fray
} 
Net, integrante de la comisión, fue designado para tal misión ${ }^{18}$. Sus gestiones en la corte debieron de ser un éxito, pues el 25 de abril de 1500 el rey Fernando el Católico escribía desde Sevilla una carta por la que disponía que los eclesiásticos seculares y regulares no abonaran aquellos dos sueldos por libra:

Don Ferrando, per la gràcia de Déu Rey de Castella, de Aragón, de Lehón, de Sicília, de Granada, de Toledo, de València, de Galícia, de Mallorques, de Sevilla, de Cerdeña, de Còrdova, de Còrsega, de Múrsia, de Jahén, dels Algarbes, de Algezira, de Gibeltar e de las Illas de Canària, Comte de Barchinona, Senyor de Viscaya e de Molina, duch de Athenas e de Neopàtria, Comte de Rosselló e de Cerdayna, Merquès de Oristany e de Gociano. Als amats e feels nostres los jurats e Clavaris de la Consignació de la Ciutat e Regne de Mallorques (...), pochs dias ha, stant nós en la Ciutat de Granada, fem, statuhim, ordenam e provehim certa pragmàtica Sanctió ab la qual, entre las altres cosas, manam que vosaltres (...) hajau (...) retenir de las pensions dels censals que aquesta universitat fa e acustuma pagar en cascun any dos sous per Liura per temps de deu anys de cascuna de las ditas pensions. Los quals dits dos sous per Liura servesquen per la Luició e quitament des dits censals (...). E nos, atesa la dita suplicació, e aquella benignament admesa, per quant la intención ostra no és stat ni és derogar en cosa alguna a las personas ecclesiàstiques, espitals e cosas pias en sos drets e interessos, ne contravenir als Sants Cànonas. Per tant, (...) conformant-nos ab la disposició de la Santa Mare Sglésia, vos dic, encarragam e manam, sots incurriment de nostra ira e indignació, e pena de mil florins de or del béns vostres (...), que als dits Capítol, Canonges, Clero, Sglésias, monastirs e personas ecclesiàstiques e religiosas, espitals e almoynas de aquexa dita Ciutat e Regne pagueu, satisfassau e respongau de las penssions del dos llurs censals íntegrament (...) e foren per vosaltres pagats si la dita nostra pragmàtica no's fora feta, ab la qual la intenció nostra no és stat ni és en res prejudicar las ditas personas ecclesiàstiques e religiosas en sos interessos (...). Data en la Ciutat de Sevilla a XXV dias del mes de abril en l'any de la Nativitat de nostre Senyor mil y cinch cents. Yo, el Rey ${ }^{19}$.

Como se puede apreciar en la carta de Fernando el Católico, el monarca estaba preocupado por no ir en contra de los derechos de la Iglesia. De hecho, en otro lugar de la misma carta, indica el rey que, en la Pragmática de Granada de I499, no ésser feta exceptió alguna del censals pertenyents als dits Capítol e Clero, lo que había permitido a las autoridades reales recaudar los dos sueldos por libra indicados. Esta medida, pues, iba en contra de la voluntad del monarca, que no deseaba perjudicar el estamento eclesiástico. Una vez advertido el equívoco, el rey dispuso la exención a todos los clérigos y estableció que se devolviera al clero el monto cobrado indebidamente.

A pesar de que las embajadas solían ser individuales, en ocasiones pudo optarse por enviar más de un representante ante el monarca. Fue el caso de la delegación despachada en enero de I5I3, de nuevo para defender las libertades y las inmunidades capitulares. En esta ocasión, se enviaron seis canónigos: Arnau Albertí, Jeroni Salom, Joan Soldevila, Pons iuniorem -seguramente, el canónigo Perot Pons-, Jeroni Mília y Llorenç Abrines. Evidentemente, como el motivo del viaje

Pere Alemany, el guardián del convento de San Francisco fray Nofre Garí, el presbítero y profesor de Teología Francesc Net, y el presbítero Gabriel Vaquer. ACM, Actas Capitulares, 01-10-ACA-017, f. 48v.

18. ACM, Actas Capitulares, 01-10-ACA-017, f. 49r.

19. ACM, Actas Capitulares, 01-10-ACA-017, ff. 59v-61r. 
era defender los intereses del Cabildo, la institución acordó que los canónigos enviados percibirían las distribuciones cotidianas ${ }^{20}$ y que contarían con ciertas exenciones, además de realizárseles un pago extraordinario de dieciséis ducados para sufragar los gastos de los cuatro meses de embajada previstos ${ }^{21}$.

En todo caso, a su regreso, los representantes capitulares debían presentarse al Cabildo e informarle del transcurso de su misión diplomática. Así lo hicieron el 25 de mayo de 1515 el canónigo Francesc Net y el franciscano fray Bartomeu de Venusta, doctor en Teología, al volver de la corte:

Coram quibus omnibus sich congregatis Capitularis, comparuerunt Reverendi dominum Ffranciscus Net, Canonicus, et magister Bartholomeus de Venusia, magister in sacra pagina, ordinis beati Ffrancisci. Et fecerunt ibidem relationem de omnibus que egerunt coram Serenissimo domino nostro Rege et eius Curia et pro negociis pro quibus ad dicta Curiam missi fuerunt per totum Clerum presentes diocesis Maioricensis ${ }^{22}$.

A raíz de estos contactos, el rey podía conceder algunas gracias o privilegios a la institución capitular, frecuentemente a cambio del pago del derecho de sello y bula, de un subsidio o del coste de la publicación del bando correspondiente ${ }^{23}$. A modo de ejemplo, el i9 de agosto de I482 el Cabildo ordenó a su procurador, Bartomeu d'Espanya, que abonara diecisiete florines y medio a cuenta de los treinta y cinco comprometidos para la confirmación, por parte del rey Fernando II, del Privilegio de 4 de enero de 1479 otorgado por su padre Juan $\mathrm{Il}^{24}$.

Igualmente fundamentales fueron las injerencias del poder real en el nombramiento de prebendados ${ }^{25}$. No hay que olvidar que los Reyes Católicos poseían y ejercieron habitualmente el derecho de súplica, que les permitía proponer sus candidatos a las prebendas vacantes en las distintas iglesias de sus territorios -incluyendo los obispados-, aunque el sumo pontífice tenía libertad para acceder, o no, a las peticiones reales ${ }^{26}$. A través de este derecho, los monarcas intentaron colocar en los distintos cargos eclesiásticos -especialmente en aquellos más estratégicos- a clérigos afines a sus intereses, aunque tampoco se olvidaron de promocionar a familiares u otros allegados, o incluso de premiar los servicios

20. Los canónigos recibían dos pagos fundamentales. En primer lugar, la porción canonical, una cantidad fija que se cobraba por el simple hecho de ostentar la prebenda. En segundo lugar, las distribuciones cotidianas, cuyo monto anual dependía de la asistencia de los canónigos a los actos corales y a sus demás obligaciones.

21. ACM, Actas Capitulares, 01-10-ACA-019, f. 113r-v.

22. ACM, Actas Capitulares, 01-10-ACA-019, f. 205r.

23. Campaner Fuertes, Álvaro: Cronicón Mayoricense. Palma, 1967, p. 186. También los jurados de Mallorca estaban obligados a dicho pago, que debió de ser bastante oneroso, desde el momento en que, en ocasiones, no se realizó la redacción de ciertas disposiciones para eludir el desembolso. PlanAs Rosselló, Antonio: Los jurados de la Ciudad y Reino de Mallorca (1249-1718). Palma, Lleonard Muntaner, editor, 2005, pp. 64-65.

24. ACM, Actas Capitulares, 01-10-ACA-016, f. 86r. Lamentablemente, no se indica el contenido del amplissimo privilegio, aunque sí que se menciona que in cuius admissione multe obiectiones pro parte Universitatis Maioricensis facte fuerunt.

25. Esta cuestión se ha desarrollado de forma más amplia en CASSANYES ROIG, Albert: «La provisión de canonicatos...», en trámite de publicación.

26. PÉreZ, Joseph: Isabel y Fernando. Los Reyes Católicos. Madrid, Nerea, 2001, p. 125. 
prestados $^{27}$. Evidentemente, las relaciones entre los monarcas y los pontífices podían resentirse a causa de las disputas en los nombramientos de los prebendados, así como por la hostilidad de la reina Isabel hacia los abades comendatarios que procuró eliminar de los monasterios castellanos ${ }^{28}$.

Sea como sea, y como ya se ha delineado antes, buena parte de las relaciones entre el Cabildo y la Corona fueron intermediadas por el lugarteniente general. El trato entre el Cabildo y los representantes de la Corona en Mallorca no fue siempre pacífico. En 1504 los canónigos tuvieron un conflicto -cuya naturaleza se desconoce- con los frailes de la orden del Santo Espíritu. El lugarteniente general, Joan Eimeric, dio apoyo a los regulares, lo que le supuso un entredicho ${ }^{29}$. Eimeric presentó un recurso ante la sede metropolitana, y el arzobispo de Valencia ${ }^{30} \mathrm{ab}$ solvió el lugarteniente de aquella pena. Sin embargo, el Cabildo apeló a la Curia Romana. El propio rey Fernando tuvo que escribir el 5 de noviembre de 1504 a los canónigos para instarles a cesar en su pretensión de condenar al oficial real:

Per çò us diem, encarragam e manam, sots pena de la fidelitat e seqüestració de les vostres temporalitats, que de continent provyau a Roma per a què dins terme de tres mesos après que la present vos será presentada, nos hajau tramesa la absolució plenària del dit nostre Loctinent General sens que, a ell, li sian fetes sobre assò despeses algunes, com ell no sia tengut de res ne li puxa ésser donada iusta culpa ${ }^{31}$.

A pesar de las amenazas del monarca de secuestrar las temporalidades de la Iglesia, el Cabildo no accedió a conceder la paz al lugarteniente hasta el i7 de octubre de $1505^{32}$. Así mismo, el 4 de enero de 1513 la institución capitular decidió denunciar la violencia realizada por el lugarteniente general -Miguel de Gurreay sus oficiales contra el canónigo Joan Soldevila el 3I de diciembre anterior. Lamentablemente, la parquedad del documento no permite conocer los detalles de aquella agresión ${ }^{33}$.

27. Lop Otín, María José: El cabildo catedralicio de Toledo en el siglo XV: aspectos institucionales y sociológicos (tesis doctoral inédita), Universidad Complutense de Madrid, 2001, pp. 352-354. Esta práctica no fue únicamente ejercida por los reyes hispanos, sino que también era habitual en los demás territorios europeos: RAPP, Francis: La Iglesia y la vida religiosa en Occidente a fines de la Edad Media. Barcelona, Labor, 1973, pp. 56-58.

28. DUMONT, Jean: op. cit. pp. 191-193.

29. Los jueces eclesiásticos tendían a utilizar las penas espirituales sin demasiado criterio en un momento en que los reyes buscaban de afianzar su justicia por sobre de la del obispo. PÉrEz, Joseph: Isabel y Fernando... pp. 123-125.

30. Cabe recordar que, desde 1492, la diócesis de Mallorca quedó ligada a la nueva archidiócesis de Valencia. Esto provocó que la superioridad jerárquica de Mallorca se hallara ahora en la ciudad del Turia, no en Roma, de la que había dependido directamente la diócesis insular hasta entonces. A pesar de ello, no se hallan demasiadas relaciones con Valencia.

31. ACM, Actas Capitulares, 01-10-ACA-018, ff. 57r-58r.

32. ACM, Actas Capitulares, 01-10-ACA-018, f. $94 \mathrm{v}$.

33. ACM, Actas Capitulares, 01-10-ACA-019, ff. 111v-112r. 


\section{ECONOMÍA TEMPORAL DE UNA INSTITUCIÓN ESPIRITUAL}

Los asuntos económicos eran uno de los que generaban más interacciones -no siempre cordiales $^{34}$ - entre la corte real y el Cabildo mallorquín. De entre estas materias, eran especialmente importantes las referentes a los diezmos ${ }^{35}$. El papa Inocencio VIII concedió a los reyes Fernando Il de Aragón e Isabel I de Castilla el producto del diezmo durante un año para dedicarlo a la conquista de Granada, atendiendo a las grandia onera expensarum quod Regem et Reginam predictos subire por tal empresa ${ }^{36}$. Asimismo, confirmó la cesión de otro diezmo, otorgada por Sixto IV, sobre los que se percibían en los reinos que conformaban la Corona de Aragón. La bula de Inocencio VIII -dada en San Pedro el 27 de marzo de I487 y recibida por el monarca en su campamento contra Málaga el 26 de junio siguiente ${ }^{37}$ - y el proceso que la acompañaba fueron leídos al Cabildo mallorquín el 2 de junio de 1488 por el bachiller en Cánones Diego de Padrosa y Alfonso de Valladolid, comisarios y tesoreros de la Santa Cruzada en las islas de Mallorca e Ibiza. Para dar cumplimiento a la bula, el protonotario apostólico Gabriele Condulmer exhortaba a los canónigos a nombrar los subcolectores requeridos para llevar a cabo la recaudación de los dos diezmos concedidos en su integridad a los monarcas ${ }^{3}$. A diferencia de otras recepciones de cartas, no se registró la deliberación que hubo a continuación. Sin embargo, el 3I de julio de I488 el Cabildo introdujo el pago de un dinero por libra para cubrir los gastos producidos pro deffensione decimarum ${ }^{39}$. Así pues, parece ser que los capitulares no aceptaron el contenido de la bula papal y que promovieron un proceso contra estos pagos, a pesar de que el documento pontificio derogaba los privilegios e inmunidades que contra la cesión de diezmos habían sido concedidos por papas precedentes. Este proceso no fue exclusivo de la diócesis de Mallorca, sino general de toda la Provincia Tarraconense, por lo que todos los obispados que la integraban se repartieron

34. Barceló CRespí, Maria: «Conflicto entre los jurados y el obispo y Cabildo de Mallorca (1478)», Anuario de Estudios Medievales, 29 (1999), pp. 24-33.

35. El Reino de Mallorca contaba con un régimen especial de diezmos. Los papas Gregorio VII (1073-1085) y Urbano II (1088-1099) habían concedido a los reyes de Aragón la percepción de todos los diezmos de los territorios que fueran conquistados a los sarracenos, siempre que se comprometieran a dotar suficientemente las iglesias que en ellos se fundaran (Belenguer CebriÀ, Ernest: Jaume I a través de la historia. Valencia, Publicacions de la Universitat de València, 2009, p. 150). Tras la conquista de Mallorca en 1229, Jaime I pactó con la Iglesia el repartimiento del diezmo, que se dividiría en dos partes: una para el rey y la otra para la Iglesia. La parroquia donde se percibía el diezmo retendría la mitad de la parte eclesiástica, mientras la otra sería divida a partes iguales entre el Cabildo y el obispo. JUAN VIDAL, Josep: «Los diezmos en la diócesis de Mallorca en el siglo XVI», Mayurqa, 22 (1989), pp. 811-816.

36. El papa también les concedió la décima parte del valor de los distintos beneficios eclesiásticos de su territorio, una cantidad que, solo en la Corona de Aragón, representaba unos veinte millones de maravedíes. Pérez, Joseph: Isabel y Fernando... p. 91.

37. Entre los testigos se menciona a Fernando del Pulgar, regio storiagrapho. ACM, Actas Capitulares, o1-10ACA-016, f 16 or.

38. ACM, Actas Capitulares, 01-10-ACA-016, ff. 158r-164v.

39. ACM, Actas Capitulares, o1-10-ACA-016, f. 168r. 
el gasto que había ocasionado. Por tanto, el Cabildo pidió al vicario general, Joan Borràs, que pagara el dinero por libra que correspondía a Mallorca. Este, sin embargo, se negó a abonar ninguna cantidad de los recursos de la Mensa Episcopal sin el permiso explícito del obispo ${ }^{40}$. Por el momento se ignora cómo se resolvió el caso, aunque el hecho de que el prelado, entonces Diego de Avellaneda, fuera también canciller de Fernando $\mathrm{Il}^{4 \mathrm{I}}$ no permite suponer que el obispo se prestara a colaborar en un recurso contrario a los intereses del monarca.

Otro de los ejes de las relaciones entre el monarca y el Cabildo mallorquín fue la bula de Cruzada. Se trataba de la predicación de la recaudación de dinero -o animar al reclutamiento de hombres- para destinarlo a la guerra contra los infieles, en el caso de la península Ibérica, contra el reino de Granada ${ }^{42}$. Esta contribución fue establecida por el papa Sixto IV en I482, y quienes realizaran el donativo pecuniario podrían verse beneficiados con una indulgencia u otras gracias pontificias ${ }^{43}$. Su sucesor Inocencio VIII continuó con su predicación en motivo de la guerra de Granada ${ }^{44}$, aunque, tras la conquista del reino nazarí, este llamamiento siguió realizándose. Así pues, cuando Alejandro VI concedió en 1500 una bula de Cruzada a los Reyes Católicos para el sustento de la Armada Real -que había sido enviada a combatir los turcos-, Fernando el Católico remitió una copia de la misma a los canónigos de Mallorca para que la publicaran y predicaran entre el pueblo. De esta manera, se esperaba conseguir los recursos necesarios para la empresa ${ }^{45}$. Asimismo, el Cabildo debía designar los comisarios de la Santa Cruzada, un cargo que recaía en un canónigo que se encargaba de la supervisión general de la bula y de todos los aspectos religiosos a ella vinculados ${ }^{46}$. Las bulas de Cruza$\mathrm{da}$, con sus respectivas indulgencias para los que realizaran aportaciones para la causa, fueron promulgadas y prorrogadas continuamente, y el Cabildo siempre las admitió, esencialmente a causa de la obediencia debida al sumo pontífice ${ }^{47}$.

Un último episodio conflictivo fue la realización del cabreo ordenado por Fernando el Católico en mayo de I5I2 a petición de los foráneos ${ }^{48}$. El 24 de noviembre de I5I4 el Cabildo eligió los prebendados que deberían encargarse de ejecutar aquellas órdenes, y fueron designados el sochantre Llorenç de Santacília

\footnotetext{
40. ACM, Actas Capitulares, 01-10-ACA-016, f. 173v.

41. Furió SAStre, Antonio: Episcopologio de la Santa Iglesia de Mallorca. Palma, Juan Guasp, 1852, p. 282.

42. Serrano Rodríguez, Eugenio y Gómez Vozmediano, Miguel Fernando: «Imprenta, dinero y fe: la impresión de bulas en el convento dominico de San Pedro Mártir de Toledo (1483-1600)», Tiempos Modernos, 7/27 (2013): <http:// tiemposmodernos.org/tm3/index.php/tm/article/viewFile/347/392> [consultado el 2 de enero de 2017], pp. 3-5.

43. Dumont, Jean: op. cit. p. 139. Véase también AznAR Vallejo, Eduardo: «Los inicios de la bula de Cruzada en Canarias», Revista Española de Derecho Canónico, 44/122 (1987), pp. 205-206.

44. Fernández Álvarez, Manuel: op. cit. p. 233

45. ACM, Actas Capitulares, 01-10-ACA-017, ff. 86r-98v.

46. Aznar Vallejo, Eduardo: op. cit. p. 207. Una elección en ACM, Actas Capitulares, 01-10-ACA-019, f. 68r.

47. ACM, Actas Capitulares, 01-10-ACA-019, f. 123v.

48. Este cabreo se había venido solicitando desde el reinado de Juan II (1458-1479) con el objetivo de revisar la contribución de ciudadanos y foráneos en los impuestos. Sobre el cabreo, JUAN VIDAL, Josep: «Mallorca en la segunda mitad...», pp. 27-28.
} 
y el canónigo Francesc Net ${ }^{49}$. Poco después, el io de enero de 1515, el Cabildo decidió enviar el canónigo Net a la corte para tratar sobre el cabreo ${ }^{50}$. La causa que había motivado aquella embajada fue que el procurador real, Francesc Burguès, dispuso que se incluyeran también en el cabreo los inmuebles sobre los cuales el Real Patrimonio no percibía derecho alguno ${ }^{51}$. Por su parte, los jurados y el Gran i General Consell también acordaron remitir un representante a la corte para tratar sobre el mismo tema. El elegido de la Universidad de Mallorca fue el canónigo Gregori Genovard ${ }^{52}$, que tuvo que pedir permiso al Cabildo para poder ausentarse de la isla y cumplir con la embajada que se le había encargado ${ }^{53}$.

\section{INQUISICIÓN, JUDÍOS Y SARRACENOS}

En el marco de un sentido providencialista del poder ${ }^{54}$, Fernando Il de Aragón e Isabel I de Castilla buscaron la unificación religiosa de sus distintos territorios. Esta unión significaba también un fortalecimiento de la monarquía, en el sentido que se formaba parte de una misma comunidad política en tanto en cuanto se participaba de una misma fe ${ }^{55}$. En primer lugar, conquistaron el último bastión musulmán en la península Ibérica, Granada, ciudad a la que entraron el 2 enero de $1492^{56}$. Aquel mismo año se llevó a cabo otro paso en la unificación religiosa con la expulsión de los judíos ${ }^{57}$. A pesar de ello, la política religiosa de los que serían conocidos como Reyes Católicos se inició una década antes, incluso de forma previa al ascenso de Fernando al trono aragonés. Así pues, hay que buscar este comienzo en el momento de la instauración de una nueva Inquisición, que permitiría a los monarcas legitimar su poder y, al mismo tiempo, utilizarla de acuerdo a sus intereses políticos, gracias a la subordinación de la institución a la Corona y al control ejercida por esta ${ }^{58}$.

49. ACM, Actas Capitulares, 01-10-ACA-019, f. 191v.

50. ACM, Actas Capitulares, o1-10-ACA-019, f. 194V.

51. Campaner Fuertes, Álvaro: op. cit. pp. 223-224.

52. La elección de los jurados recayó en Gregori Genovard porque se consideraba que era persona que té més veus. BARCeló CRespí, Maria: «Agnès de Pacs i l'entorn humanista», Memòries de la Reial Acadèmia Mallorquina d'Estudis Genealògics, Heràldics i Històrics, 10 (2000), p. 44.

53. ACM, Actas Capitulares, o1-10-ACA-019, f. 196v.

54. Fernández Álvarez, Manuel: op. cit. pp. 537-539.

55. PÉreZ, Joseph: Historia de una tragedia. La expulsión de los judíos de España. Barcelona, Crítica, 2009, pp. 129-131.

56. De esta manera, se cumplieron los pactos matrimoniales entre Isabel de Castilla y Fernando de Aragón, que obligaban las partes a combatir contra el reino nazarí. VAL VALDIVIESO, María Isabel del: «Isabel la Católica. Una mujer para el trono de Castilla», Memòries de la Reial Acadèmia Mallorquina d’Estudis Genealògics, Heràldics i Històrics, 14 (2004), p. 16.

57. Ha habido un cierto debate sobre a cuál de los reyes correspondió la iniciativa de la expulsión de los judíos. Luis Fernández Álvarez, quizá para evitar la responsabilidad de Isabel, hace derivar el edicto de expulsión de Fernando II. Fernández Álvarez, Manuel: op. cit. pp. 302-303. En cambio, otros autores, como el cronista Eliyahu bar Elqanah Capsali, consideran que la iniciativa partió de la reina Isabel. SuÁrEz FERNÁNDEZ, Luis: La expulsión de los judíos. Un problema europeo. Barcelona, Ariel, 2012, pp. 410-411. Véase, igualmente, para este episodio, MARCU, Valeriu: La expulsión de los judíos de España. Sevilla, Renacimiento, 2002; y PÉrEZ, Joseph: Historia de una tragedia...

58. Galende Díaz, Juan Carlos y Cabezas Fontanilla, Susana: «Historia y documentación del Santo Oficio 
El I de noviembre de I478, el papa Sixto IV, mediante la bula Exigit sinceræ devotioni ${ }^{59}$, autorizó a los reyes la designación de un par de eclesiásticos que actuaran como inquisidores en la Corona de Castilla. Esta concesión vino a suponer la implantación de una nueva Inquisición supeditada a los monarcas ${ }^{60}$, que, paulatinamente, se fue estableciendo también en los territorios de la Corona de Aragón ${ }^{61}$. La instauración de la Inquisición moderna en Mallorca no fue una tarea fácil, aunque no estuvo sujeta a violencia, como sí sucedió en otros lugares ${ }^{62}$. Las autoridades mallorquinas eran conscientes del riesgo que entrañaba para la economía insular la nueva institución inquisitorial, pues perseguía la herejía y tenía entre sus principales sospechosos a los conversos, un grupo social que se caracterizaba por su actividad e importancia económicas. A pesar de la oposición de los jurados, que escribieron al monarca en I 487 sobre esta cuestión, el año siguiente llegaron a Mallorca los dos primeros inquisidores modernos, Pedro Pérez de Munebrega y Sancho Marín ${ }^{63}$. La Inquisición presentó una elevada actividad durante sus primeros años, y en I 490 ya se llevaron a cabo tres autos de fe. Sin embargo, a partir de 1515 su actividad decayó, aunque se mantuvo importante hasta $1534^{64}$.

No parece que el Cabildo catedralicio viviera como una amenaza la llegada de la Inquisición en Mallorca, aunque tampoco hay evidencias que demuestren que se implicara en ella. El 6 de febrero de 1489 los canónigos encargaron al vicario general sede vacante que tratara todos los negocios referentes al Tribunal de la Santa Inquisición con el inquisidor Sancho Marín, que era doctor en ambos Derechos y clérigo de Zaragoza. Además, el Cabildo se comprometió a informar al inquisidor de todas las prácticas heréticas y apostasías de las que tuviera conocimiento ${ }^{65}$. Por otro lado, algunos canónigos formaron parte del Santo Oficio y ejercieron en él. El caso más conocido quizá sea el de Arnau Albertí, que fue inquisidor entre 1520 y $1527^{66}$. También es posible que el canónigo Juan de Astorga sea el inquisidor del mismo nombre que actuó entre I490 y I49I. Igualmente pudo haber sido inquisidor Pere Gual, que ejercería hacia I494. Ya en el siglo XVI, los canónigos

\footnotetext{
español: el periodo fundacional», III Jornadas Científicas Sobre Documentación en época de los Reyes Católicos, Madrid, 2004, Galende Díaz, Juan Carlos (dir.), Madrid, Universidad Complutense de Madrid, 2004, pp. 122-125.

59. Fita Colomé, Fidel: «Nuevas fuentes para escribir la historia de los judíos españoles: bulas inéditas de Sixto IV e Inocencio VIII», Boletín de la Real Academia de la Historia, 15 (1889), pp. 447-458.

6o. El 29 de enero de 1482 el papa Sixto IV, al conocer la severidad con que actuaban los inquisidores, quiso supeditar la Inquisición castellana a los obispos. Este hecho dio lugar a un concordato el 3 de julio siguiente por el que los reyes consiguieron conservar su autoridad sobre el tribunal. Fernández ÁlvareZ, Manuel: op. cit. pp. 282-288.

61. Escudero López, José Antonio: «Los Reyes Católicos y el establecimiento de la Inquisición», Anuario de Estudios Atlánticos, 50/1 (2004), pp. 386-393. En el marco de la monarquía católica, la Inquisición fue la única institución comuna en las coronas de Castilla y Aragón. CASASnOvas CAMPS, Miquel Àngel: op. cit. p. 224.

62. Santamaría ArÁndez, Álvaro: «Sobre la condición de los conversos y chuetas de Mallorca», Espacio, tiempo y forma. Serie III, Historia Medieval, 10 (1997), pp. 236-237.

63. Colom Palmer, Mateu: La Inquisició a Mallorca (1488-1578). Barcelona, Curial, 1992, pp. 20-23.

64. Idem, pp. 28-42. Véase también Mateu Mairata, Gabriel: Obispos de Mallorca. Palma, Ediciones Cort, 1985, pp. 189-19o.

65. ACM, Actas Capitulares, 01-10-ACA-016, f. 176r.

66. Barceló Crespí, Maria y Ensenyat Pujol, Gabriel: Clergues il/lustrats. Un cercle humanista a l'entorn de la Seu de Mallorca (1450-1550). Palma, Publicacions Catedral de Mallorca, 2013, p. 118.
} 
Nicolau Muntanyans y Gregori Genovard fueron lugartenientes del inquisidor entre I53I y I534, y Guillem Grua, en calidad de vicario general, ejerció como visitador inquisitorial en I5I9.

Los principales problemas entre Cabildo y Santo Oficio se dieron por motivos económicos. El Tribunal de la Inquisición debía financiarse, entre otros recursos, a partir de las rentas de una canonjía, que tenía que unírsele. En I50 A Alejandro VI, a petición de los Reyes Católicos, dispuso que se suprimiera un canonicato en cada catedral hispana para destinar sus rentas a la Inquisición. Aquel mismo año falleció en Mallorca el canónigo Mateu Àlber, la provisión de cuya canonjía no fue sencilla, pues existían numerosos clérigos expectantes y otros con derechos a la prebenda. El rey, haciendo uso de un indulto apostólico, había decidido otorgar las rentas de la canonjía a la Santa Inquisición de Mallorca. Sin embargo, los canónigos se opusieron a que el inquisidor tomara posesión de la prebenda. Fernando el Católico escribió al Cabildo el 3i de marzo de i5or desde Granada para exigirle que entregara el canonicato al Santo Oficio:

A los amados nuestros los Capítulo y Canónigos de la Seu de Mallorques.

El Rey.

Amados nuestros. Sabido havemos que, por muerte de mossèn Àlber, Canónigo d'essa iglesia, ha vacado la Canongía que en ella tenía, a la qual stava nombrado el licenciado pariente Inquisidor en virtut del Indulto a nos concedido por nuestro muy sancto padre para la colocación de los Inquisidores y otros oficiales y ministros del dicho Sancto Officio. E que como quier que por parte del dicho Inquisidor se ha procurado de tomar la possessión de la dicha Canongía, vosotros havéys puesto en ello algún impedimento, de lo qual, si así es, nos maravillamos, porque sabiendo quan favorecido es el dicho indulto y que deroga todas y qualesquier gracias y restuptos apostólicos, no devades differir la dicha posssesión. Y porque el dicho Inquisidor es persona que ha mucho servido y sirve en el dicho Sancto Officio, y nuestra voluntat es que pues la dicha Canongía le pertenece con iusticia le sea dada la possessión pacífica d'ella. Por ende, encargamos y mandamos vos que si al tiempo que esta recibiedes no le havéys dado la possessión de la dicha Canongía, luego a la hora se la déys y fagáys dar sin le poner ni consentir que le sia puesto en ella impedimento alguno, acudiendo le con los fructos y rentas d'ella, como es razón, que demás de les faser lo debido lo recebiremos en servicio y a lo contrario en ninguna manera daríamos lugar. Data en la Ciutad de Granada a XXII días de Março del año M D y uno ${ }^{67}$.

A pesar de ello, la pretensión real no se realizó, y el I7 de mayo de I50I el canonicato fue colacionado a Pere Pereta. Así pues, en la práctica, la Inquisición mallorquina no se nutrió de rentas capitulares hasta $1582^{68}$.

Por lo que se refiere a la cuestión judía, el Cabildo no tuvo vinculación alguna con los hebraicos. Teóricamente, no existía ninguna comunidad judía en Mallorca desde las conversiones masivas de $1435^{69}$ y la prohibición de asentamientos de

67. ACM, Actas Capitulares, 01-10-ACA-017, f. 82r-v.

68. Colom Palmer, Mateu: op. cit. pp. 125-128.

69. Sobre este episodio, véase, por ejemplo, PÉREZ MARTínez, Lorenzo (ed.): Reivindicación de los judíos mallorquines. Documentos para su estudio, I. Palma, 1983, p.45; CORTÈs i CORTÈs, Gabriel: Historia de los judíos mallorquines y de sus 
israelitas en la isla por más de quince días dispuesta por la reina María el io de marzo de $1436^{70}$. Por este motivo, el decreto de expulsión de los judíos de 3I de marzo de $1492^{71}$ no tuvo ningún efecto en Mallorca. Sin embargo, los conversos mallorquines de finales del siglo XV mantenían todavía algunas prácticas hebraicas, tales como la observación de ciertos ayunos en fechas señaladas, el consumo -o abstinencia- de determinados alimentos o los rituales funerarios particulares ${ }^{72}$. A pesar de ello, no fueron molestados desde las instituciones por este motivo, puesto que, a diferencia de sus homólogos castellanos, no había -teóricamente- judíos que pudieran provocar la «rejudeización» de los conversos, que era el efecto que las autoridades pretendían evitar ${ }^{73}$.

Más problemáticos, en cambio, fueron los musulmanes. Uno de los principales ámbitos en que se desarrolló la política de Fernando Il de Aragón fue la lucha contra los piratas y corsarios sarracenos - pero también genoveses- que atacaban las costas hispánicas desde el norte de África ${ }^{74}$. Así pues, el rey decidió llevar a cabo una política de expansión en la zona que servía de base a los corsarios. A tal efecto, buscó la ocupación de determinados puntos estratégicos en la costa -discrepando con el cardenal Cisneros, partidario de una penetración interior ${ }^{75}$ mediante una ofensiva que empezó en julio de 1508 con el control del Peñón de Vélez la Gomera ${ }^{76}$. El archipiélago balear fue una de las zonas más castigadas por los ataques de los agarenos, pues su proximidad con Argel hacía de las islas un enclave fácilmente asequible. Por este motivo, Mallorca colaboró activamente en la política de contención de la piratería y en las operaciones contra las plazas norteafricanas, como la conquista de Orán o Bugía ${ }^{77}$.

Los canónigos participaron también en la lucha contra el infiel musulmán protagonizada por Fernando el Católico. Ya se ha comentado la importancia que tenía la Iglesia en la recaudación de recursos para la guerra a través de la predicación de la bula de Cruzada, mediante la cual toda donación era premiada con una indulgencia. Por otro lado, también se llevaban a cabo grandes festejos en

descendientes cristianos. Palma, Miquel Font, editor, 1985, pp. 96-97; e IsAACs, A. Lionel: Els jueus de Mallorca. Palma, Miquel Font, editor, 1986, pp. 110-113.

70. CORTÈs i Cortès, Gabriel: op. cit. p. 97.

71. Se emitieron dos edictos, uno para Castilla y el otro para Aragón. Los dos edictos reales y el inspirado por fray Tomás de Torquemada, debidamente transcritos, pueden verse en PérEZ, Joseph: Historia de una tragedia... pp. 143-157.

72. Colom Palmer, Mateu: op. cit. pp. 56-62.

73. DUMONT, Jean: op. cit. pp. 56-57; EdWARDs, John: op. cit. p. 356.

74. Bello León, Juan Manuel: «Apuntes para el estudio de la influencia del corso y la piratería en la política exterior de los Reyes Católicos», Historia. Instituciones. Documentos, 23 (1996), pp. 77-84.

75. Alonso Acero, Beatriz: Cisneros y la conquista española del norte de África: cruzada, política y arte de la guerra. Madrid, Ministerio de Defensa, 2005.

76. VV.AA.: Historia de Marruecos. Madrid, Consejería de Educación y Ciencia, Embajada de España en Marruecos, 1996, p. 78.

77. DEYà BAuZÀ, Miquel Josep: «Entre la toma de Orán y los pactos con Argel: las Baleares y la conquista de Bugía», en Bunes IbarRa, Miguel Ángel de y Alonso Acero, Beatriz (coords.): Orán. Historia de la corte chica. Madrid, Polifemo, 2011, pp. 55-82. A pesar de estas hostilidades, el norte de África fue una de las principales plazas comerciales de Mallorca. JUAN VIDAL, Josep: «Mallorca en la segunda mitad...», pp. 28 y 31-32. 
aquellas ocasiones en que las tropas cristianas obtenían una victoria ante los ejércitos infieles. Cuando en mayo de I483 llegó la noticia del éxito de las tropas reales contra «el rey joven de Granada» -Boabdil el Chico- en la batalla de Lucena, se celebraron procesiones y un solemne tedeum en la catedral ${ }^{78}$.

Más destacada fue la conquista de la ciudad de Bugía por parte de Fernando Il el 6 de enero de I5Io, que suponía una cierta tranquilidad para las islas desde el momento en que la ciudad era una de las principales bases corsarias africanas. De hecho, la implicación de Mallorca en la defensa de Bugía fue muy notable durante todo el período en que esta estuvo bajo dominio hispánico. Así pues, en I5I5, el Gran i General Consell sufragó una expedición de defensa para socorrer el lugar ante los ataques de Barbarroja ${ }^{79}$. Evidentemente, la isla era el territorio más cercano al norte de África y, por tanto, el que estaba más expuesto a los ataques corsarios. El control de la zona, más que a un interés religioso, respondía a motivaciones de seguridad, y la presencia mallorquina en la plaza fue constante hasta su pérdida en $\mathbf{5} 55$.

En el momento de la conquista de Bugía, se daba la circunstancia que había sido nombrado obispo de la misma el mallorquín Miquel Morro, natural de la villa de Inca. El prelado permanecía en Mallorca a la espera de poder pasar a su diócesis ${ }^{80}$. Al recibir la noticia de la ocupación de Bugía, el Cabildo catedralicio mallorquín decidió conceder la gracia de percibir las distribuciones cotidianas durante un año a todos los canónigos y presbíteros que se embarcaran hacia aquella plaza acompañando al nuevo prelado ${ }^{81}$. De este modo, Miquel Morro pasó a la ciudad norteafricana juntamente a los canónigos Joan Borràs y Llorenç Abrines y al beneficiado Jaume Vanrell ${ }^{82}$. Por otro lado, el Cabildo de Mallorca era también consciente de la necesidad de recristianizar la diócesis africana, de modo que decidió prestar al obispo Morro vestimenta, calices, cruces et alia necessaria pro divino cultu $^{83}$. La donación se materializó a finales del mes de enero de I5Io mediante la realización de un inventario, redactado en catalán:

Et primo, uns vestiments, sò és casulla, dos domàtigas de vellut morat ab parxos de or, o trenas starrats ja usats, y una capa.

Item, altra capa de vellut morat y vermell molt usat.

78. Campaner Fuertes, Álvaro: op. cit. p. 190. Celebraciones similares tenían lugar ante cualquier victoria del monarca, como la acaecida en 1479 contra los portugueses y los castellanos rebeldes. BARCELÓ CRESPí, Maria: «Conflicto entre los jurados...»p. 26.

79. Dameto, Joan, Mut, Vicenç y Alemany, Jeroni: Historia General del Reino de Mallorca. Palma, Imprenta Nacional á cargo de D. Juan Guasp y Pascual, 1841, III, pp. 465-468; CASASNovas CAmpS, Miquel Àngel: op. cit. p. 219.

80. VILlanueva, Jaime: Viage literario a las iglesias de España. Tomo XXII. Viage á Mallorca. Madrid, Imprenta de la Real Academia de la Historia, 1852, pp. 96-97. Algunos autores afirman, erróneamente, que Morro fue obispo de Mallorca. BARBERI, Josep: Vida de la venerable madre sor Clara Andreu, natural de Palma, capital del Reyno de Mallorca, religiosa gerónima en el monasterio de San Bartolomé de la villa de Inca, con un apéndice histórico de dicha villa. Palma, Imprenta de Melchor Guasp, 1807, pp. 44-45.

81. ACM, Actas Capitulares, 01-10-ACA-018, f. 206r.

82. ACM, Actas Capitulares, 01-10-ACA-018, f. 206v y $209 \mathrm{r}$.

83. ACM, Actas Capitulares, 01-10-ACA-018, f. 206r. 
Item, dos stolas, tres mamples y dos collas de seda listada, sò és verd y blanch.

Item, uns camús ab parament de carmesí, sò és amit y sinyell.

Item, un pali de vellut lesonat de la passió, salutació y Los tres Reys, tot figudas de or, ja usat. Item, altre pali de tela blanque de la asumptió de nostra dona.

Item, una tovallola de domàs blanch brodada de or ab floradura de seda blanqua y vermella.

Item, un libre apellat Oracioner ab las capítolas de pregamí ab posts y cubertas negres.

Item, altra libre; són són diversos oficis de pregamí.

Item, altra libre [rayado: deg] de pregamins, missal y con/sueta vella que era prestat a Sineu, y fonch restituït.

Item, altre libre apellat Ordinari per bateigs, uncions per núptias y processional y altres officis.

Item, altre libre de pregamins apellat Ofrecier.

Item, un feristol [rayado: ant] alt de fust de noguer ab sa roda.

Item, una creu de crestall ab lo Ihs al mitg asmaltat.

Item, un retaula de fust deurat nou de la asumptió de nostra dona, ab dos ymatges, sò és de sant Jordi y sant Honofre.

Item, un postier ab la cama trencada qui trau dos formas.

Item, un càlzer de argent ab sa petena, ab senyal de peres de pes de XXI onza y tres quarts, y la petena té senyal de una creu y mà qui vol senyar.

Item, altre càlzer de argent ab se petena ab vuyt senyals asmaltats al peu, ab senyal de cervos en lo botó y la petena ab tres asmalts, y lo del mitg és lo Ihs en creu, Johan y Maria y altres dos lochs de asmalts que ma(?) pren(?), de pes de XXXVII onzas y un quart.

Item, una capsa de argent deurada, ab un pom y croheta sobre la cuberta, de pes de XIII onzas un quart.

Item, dos trossos de Vera Creu, que li fonch dada presents los Reverends Cabiscol, mossèn Armadans, mossèn Borràs y mossèn Abrines, Canonges, y altres diversos preveres ${ }^{84}$.

Como se puede observar, el Cabildo catedralicio no cedió a Miquel Morro objetos litúrgicos nuevos, sino que la mayoría de bienes que se le prestaron eran usados. La única excepción la constituye un retablo con la imagen de la Asunción de María, que es, precisamente, la titular de la catedral de Mallorca. A la imagen de la Virgen la flanqueaban san Jorge y san Onofre, dos santos que contaban con una cierta devoción en la isla. Asimismo, hay que destacar también la cesión de dos trozos de la reliquia de la Vera Cruz, seguramente con la intención de servir de base al culto cristiano, siempre necesitado de reliquias ${ }^{85}$. Con el objeto de certificar la veracidad de la misma, esta fue entregada en presencia de cuatro canónigos y

84. ACM, Actas Capitulares, 01-10-ACA-018, ff. 207r-208r.

85. García de LA Borbolla, Ángeles: «El culto y devoción del lignum crucis en los reinos occidentales de la península ibérica (VII-XV)», Pecia. Ressources en medievistique, 8/11 (2005), pp. 565-600. 
un número indeterminado de presbíteros. Sea como sea, el obispo Morro se obligó a devolver todos y cada uno de los objetos relacionados en el inventario y, como garantía, estableció todos sus bienes particulares ${ }^{86}$.

El Cabildo no solo festejaba las grandes victorias militares del monarca contra los sarracenos, sino también las que se producían en Mallorca. Un caso especial sucedió en febrero de I509. El día 9 llegaron al islote de Cabrera dos galeras de corsarios africanos, que capturaron un total de veintidós pescadores mallorquines. Sin embargo, las galeras recalaron unos días en la isla, lo que permitió a las autoridades movilizar doscientos hombres al mando de Jaume Burguès. El día I3 de febrero, los corsarios fueron capturados ${ }^{87}$. La presa fue altamente celebrada, por lo que el i5 de febrero el Cabildo decidió recibir a la expedición con todos los honores: se haría sonar la campana mayor de la catedral y se cantaría un tedeum con órgano. Además, el día siguiente, tras la misa, se llevaría a cabo una solemne procesión que sería observada por los cautivos desde la plaza de $\operatorname{Cort}^{88}$. No en vano, la conversión de sarracenos a la fe cristiana sería uno de los temas principales, aunque poco tratado -según la documentación- en las sesiones capitulares. Sin embargo, en una acta vacía del 27 de junio de 1515 se halla una nota marginal en la que se indica que se trató super baptismo filii Regis mauri ${ }^{89}$, sin que sea posible identificar, en estos momentos, a quién puede hacer referencia.

\section{CABILDO Y MONARQUÍA EN LA PROMOCIÓN DEL LULISMO}

La doctrina luliana tuvo una importante incidencia en la isla de Mallorca. Hay que recordar que, a partir del siglo XV, los intelectuales mallorquines adoptaron el lulismo, tras un proceso de identificación entre ellos y Ramon Llull tanto por sus orígenes territoriales como sociales ${ }^{90}$. Este mismo interés luliano también se dio entre los canónigos del Cabildo catedralicio ${ }^{91}$, aunque, en conjunto, el colectivo capitular no puede ser considerado una institución lulista en estos momentos. De hecho, el Cabildo no inició los trabajos para lograr la canonización del filósofo hasta el siglo XVII, a pesar de la veneración que tenía Llull como santo local ${ }^{92}$.

86. ACM, Actas Capitulares, 01-10-ACA-018, f. 208r.

87. Campaner Fuertes, Álvaro: op. cit. p. 222.

88. ACM, Actas Capitulares, 01-10-ACA-018, ff. 172v-173r.

89. ACM, Actas Capitulares, 01-10-ACA-019, f. 209r.

90. Barceló Crespí, Maria y Ensenyat Pujol, Gabriel: Els nous horitzons culturals a Mallorca al final de l'Edat Mitjana. Palma, Documenta Balear, 2000, pp. 102-103.

91. Barceló Crespí, Maria y Ensenyat Pujol, Gabriel: Clergues il.lustrats... p. 170.

92. Hillgarth, Jocelyn Nigel: «La cultura de las Islas Baleares en la época del descubrimiento», Congrés Internacional d'Estudis Històrics. Les Illes Balears i Amèrica. Volum I. Palma, gener, 1992, PIÑA Homs, Román (coord.), Palma, Institut d'Estudis Baleàrics, 1992, p. 43. 
La protección del lulismo -que se mezcló también con elementos procedentes del escotismo a través de Pere Daguí13 - correspondió a la orden de los franciscanos, a la que Ramon Llull se había unido espiritualmente -a pesar de no profesar nunca como fraile- y en cuyo convento reposaban sus restos. Sin embargo, el siglo $\mathrm{XV}$ fue una centuria difícil para los frailes menores. Es sabido que el cuatrocientos fue el momento en que se produjo la definitiva separación entre franciscanos conventuales y observantes, y los Reyes Católicos, de la misma forma que sus antecesores -especialmente castellanos- promovieron la adopción de la Observancia por los distintos conventos ${ }^{94}$. Esto causó algún problema en Mallorca, donde la Observancia llegó a partir de la reforma llevada a cabo por Bartomeu Catany a mediados de siglo ${ }^{95}$. Así pues, los franciscanos claustrales obtuvieron del cardenal Domenico Grimani, protector de la orden de frailes menores, un monitorio por el que se disponía la expulsión de los observantes del convento de San Francisco de Mallorca. El mandato fue ejecutado inmediatamente por el Cabildo, sin consultar, de forma previa, el monarca. Esto provocó una reacción airada de Fernando el Católico, de lo qual certament tenim tant de anuig e sentiment que no ho podem ab paciència tollerar, pues el monitorio había sido denunciado por los frailes observantes de Zaragoza, Tudela y otros lugares y, por tanto, suspendido ${ }^{96}$. En cualquier caso, los claustrales se mantuvieron en el convento de Mallorca, del que no fueron expulsados hasta la reforma de Felipe II de $1567^{97}$.

Por otro lado, los franciscanos observantes, en su voluntad de actuar de acuerdo con la pobreza original de la orden, decidieron abandonar los estudios, postura que mantuvieron hasta el último tercio del siglo XVI. A pesar de ello, el lulismo pudo mantenerse gracias a la fundación del Estudio General Luliano. Este fue autorizado por Fernando Il mediante el Privilegio de Córdoba de 30 de agosto de $1483^{98}$. La creación de esta institución había sido solicitada por los jurados de

93. Ramis Barceló, Rafael: «En torno al escoto-lulismo de Pere Daguí», Medievalia, 16 (2013), pp. 235-264; CASSANYES RoIG, Albert y RAmis BARCELó, Rafael: «Fray Junípero Serra y la Universidad Luliana y Literaria de Mallorca», Archivum Franciscanum Historicum, 107 (2014), pp. 428-432.

94. Andrés Martín, Melquíades: «La espiritualidad franciscana en España en tiempos de las observancias (1380-1517)», Studia Historica. Historia Moderna, 6 (1988), pp. 465-479; CANTERA Montenegro, Margarita: «Las órdenes religiosas», Medievalismo, 13-14 (2004), pp. 115-123; RoJO ALIQUE, Francisco Javier: «Reforma religiosa, sociedad y política en la Baja Edad Media: el ejemplo de San Francisco de Palencia en el siglo XV》, Hispania Sacra, LIX/120 (2007), pp. 471-474 y $486-491$.

95. TriAs MerCANT, Sebastià: Història del pensament a Mallorca. Volum 1. Del orígens al segle XIX. Palma, Editorial Moll, 1985, pp. 108-110. Ver también Furió SASTRE, Antonio: Vida del bendito padre fray Bartolomé Catany. Palma, Imprenta a cargo de D. Juan Guasp, 1851.

96. ACM, Actas Capitulares, 01-10-ACA-018, f. 57r-v. Casos similares se observan en otros territorios de la Monarquía Hispánica. Rojo AlıQUe, Francisco Javier: op. cit. p. 471.

97. Cassanyes Roig, Albert y Ramis Barceló, Rafael: «Los grados en Teología escotista en la Universidad Luliana y Literaria de Mallorca (1692-1823)», Archivo Ibero-Americano, 74/277-278 (2014), p. 8.

98. Sobre la fundación de la institución, ya son clásicos los estudios de Lladó i Ferragut, Jaume: Historia del Estudio General Luliano y de la Real y Pontificia Universidad Literaria de Mallorca. Palma, Ediciones Cort, 1973, pp. 39-45; y SANTAMARÍA ARÁNDEZ, Álvaro: La promoción universitaria en Mallorca. Época de Fernando el Católico (1479-1516). Palma, Universitat de Palma de Mallorca, 1983, pp. 85-137. Más reciente es BARCELó Crespí, Maria y URGELL HeRnÁNDEZ, Ricard: «La Universitat de Mallorca: origen i evolució fins el segle XVIII», en BusQUETA i RIU, Joan J. y PEMÁN GAVÍN, Juan (coords.): Les universitats de la Corona d'Aragó, ahir i avui. Estudis històrics. Barcelona, Pòrtic, 2002, pp. 160-172. También es muy sugerente el artículo de RAMIS BARCELó, Rafael: «Sobre la denominación histórica de la universidad 
Mallorca, animados por las donaciones de Beatriu de Pinós ${ }^{99}$ y Agnès de Pacs $^{\mathrm{Ioo}}$. Las autoridades municipales esgrimieron numerosos motivos para justificar la fundación del centro, entre los cuales la elevación del nivel cultural del Reino de Mallorca, la mayor facilidad de acceso de los mallorquines de la Parte Forana a los estudios superiores o el hecho de que los insulares no tendrían que enfrontarse a los peligros del mar -esto es, los corsarios- a la hora de trasladarse a las universidades peninsulares o a los muy frecuentados centros italianos ${ }^{\text {Ior }}$. Sin embargo, uno de los motivos principales de la petición de los jurados era la defensa del lulismo. De hecho, hay que tener presente que la Universidad de Mallorca no contaba con recursos suficientes como para garantizar el correcto funcionamiento del Estudio General Luliano, pero, sin embargo, insistió en su fundación. El objetivo sería promover el lulismo en un momento en que esta doctrina se iba agotando en Europa ${ }^{\mathrm{IO} 2}$ y, sobre todo, defenderlo ante los posibles ataques de la Inquisición y de dominicos como el inquisidor Guillem Caselles ${ }^{103}$.

Además de facilitar la constitución del Estudio General Luliano y de defenderlo ante prácticas amenazantes para su funcionamiento ${ }^{104}$, Fernando Il también favoreció el lulismo mediante la concesión de privilegios para fomentar la enseñanza de la doctrina de Ramon Llull, siguiendo la estela de sus antecesores en el trono. Por ejemplo, en 1500 autorizó al cisterciense Jaume Gener a fundar una escuela luliana en Valencia ${ }^{105}$. Algunos años antes, concretamente en I492, el monarca dio otra muestra de promoción luliana mediante la concesión de la ermita de Miramar a Bartomeu Caldentey para que instaurara allí un centro luliano, similar al que ya había fundado el propio Ramon Llull en $1276^{106}$. No hay ninguna duda

de Mallorca», Cuadernos del Instituto Antonio de Nebrija, 13/2 (2010), pp. 237-263, en el que se estudia la institución a partir de su nombre.

99. SANTAMARÍA ARÁNDez, Álvaro: «La donación proluliana de Beatriu de Pinós», Bolletí de la Societat Arqueològica Lul.liana, 35 (1976), pp. 50-53; LLABRÉs QuINTANA, Gabriel: «Testamento de doña Beatriz de Pinós», Bolletí de la Societat Arqueològica Lul.liana, 20 (1925), pp. 305-310.

100. Barceló Crespí, Maria: «Agnès de Pacs...» pp. 21-36. Véase también Vargas Martínez, Ana: «Beatriu de Pinós y Agnès de Pacs: el origen femenino de las escuelas lulianas en la Mallorca del siglo XV», en DíAz SánCHEZ, Pilar, Franco Rubio, Gloria y Fuentes Pérez, María Jesús (eds.): Impulsando la historia desde la historia de las mujeres. Huelva, Universidad de Huelva, 2012, pp. 409-415.

101. Ramis BARCeló, Rafael: «Peregrinatio academica: legistas y canonistas de la Corona de Aragón en las universidades italianas durante el Renacimiento», Miscellanea Historico-iuridica, 13/1 (2014), pp. 35-66.

102. Lladonosa i Pujol, Josep: Relacions entre Mallorca i Lleida a l'època medieval. Barcelona, Rafael Dalmau, Editor, 1976, p. 47.

103. Ramis BARCeló, Rafael: «Sobre la denominación histórica...» pp. 243-244; EnSEnYAT Pujol, Gabriel: «Les institucions d'alta cultura: de l'Estudi General Lul-lià a la Universitat Literària», en BONNER, Anthony y BujOSA HOMAR, Francesc (dirs.): Història de la Ciència a les Illes Balears. Volum II. El Renaixement. Palma, Conselleria d'Economia, Hisenda i Innovació, 2006, p. 21.

104. El apoyo del monarca al Estudio General Luliano se refleja también en su intervención para evitar la amortización de la cátedra fundada por Agnès de Pacs para dotar un arcedianato en la catedral. BARCELó CRESPí, Maria y URGELL HERNÁNDEZ, Ricard: op. cit. pp. 169-170 y 172.

105. Ramis BARCELó, Rafael: «Un esbozo cartográfico del lulismo universitario y escolar en los reinos hispánicos», Cuadernos del Instituto Antonio de Nebrija, 15/1 (2012), p. 76.

106. Ramon Llull había proyectado y fundado en Miramar un colegio para la formación de misioneros, en el que trece frailes aprendían lengua y cultura árabes. La bibliografía sobre dicha institución es abundante. Véase, a modo de 
de la adhesión del rey católico a la doctrina luliana, quizá influido por el maestro Pere Daguí, a la sazón capellán realio7.

Esta actividad proluliana del monarca contrastó con una cierta apatía por parte del Cabildo, que no destacó, precisamente, por encabezar la defensa de la doctrina de Llull ${ }^{108}$. Esto, sin embargo, no le impedía asistir a determinadas fiestas de carácter luliano, como la celebrada en Mallorca el I5 de mayo de 1502 en motivo de los avances que la ciencia luliana había hecho en Roma y Sevilla gracias a Pere Daguí, que había logrado privilegios y aprobaciones por parte del papa y del propio rey ${ }^{\mathrm{ro}}$. Por otro lado, algunos de los miembros capitulares, de manera individual, sí que destacaron como lulistas. El más conocido, sin duda, fue Esperandéu Espanyol, que fue enviado a Roma por el Cabildo en diferentes misiones prolulianas y, además, era patrono de la cátedra luliana instituida por su tía Agnès de Pacs ${ }^{\text {II }}$. Otro importante canónigo lulista fue su sobrino Gregori Genovard, que compatibilizó su canonicato con la cátedra de doctrina luliana y el rectorado del Estudio General Luliano. Por otro lado, también promovió la edición del Blaquerna de Ramon Llull ${ }^{11}$, que fue impresa en Valencia en I5I9. Sin embargo, una de las aportaciones más destacables de Genovard en el campo del lulismo fue su embajada ante el monarca, remitida por el Gran i General Consell de Mallorca para la defensa de la donación proluliana de Beatriu de Pinós, que había sido denunciada por su hija Estefania ${ }^{\mathrm{II} 2}$. Finalmente, es necesario mencionar a Arnau Albertí, futuro obispo de Patti (I534-I544), que escribió varios comentarios a la doctrina de Ramon Llull ${ }^{113}$.

ejemplo, Garcías Palou, Sebastià: El Miramar de Ramon Llull. Palma, Institut d’Estudis Baleàrics, CSIC, 1977, así como VV.AA.: Actas del I/ Congreso Internacional de Lulismo. Palma, Maioricensis Schola Lullistica, 1979, 3 vols.

107. PÉrez Martínez, Lorenzo: «El maestro Daguí y el lulismo mallorquín de fines del siglo XV», Estudios Lulianos, 12 (1960), pp. 291-306. Daguí también tuvo un cierto influjo sobre el cardenal Cisneros; no en vano, en 1508 el cardenal llamó a Nicolau de Pacs para que impartiera filosofía y teología lulianas en la Universidad de Alcalá de Henares que acababa de fundar. RAmis BARCELó, Rafael: «Un esbozo cartográfico...» pp. 75 y 81-82.

108. Cassanyes RoIg, Albert: «El Capítol catedralici de Ramon Llull (1232-1316)», en Fullana Puigserver, Pere y Gambús SaIz, Mercè (coords.): Ramon Llull i la Seu de Mallorca. Palma, Publicacions Catedral de Mallorca, 2016, pp. 64-69.

109. Campaner Fuertes, Álvaro: op. cit. p. 219; Barceló Crespí, Maria y Urgell Hernández, Ricard: op. cit. p. 171.

110. La bibliografía sobre Esperandéu Espanyol es bastante numerosa. La semblanza biográfica más reciente es Barceló Crespí, Maria y EnSenyat Pujol, Gabriel: Clergues il.lustrats... pp. 23-36. Véase también Barceló Crespí, Maria y ENSENYAT PUjOL, Gabriel: «Esperandeu Espanyol, un canonge del segle XV amb interessos humanistes i lul.listes», Bolletí de la Societat Arqueològica Lul.liana, 66 (2010), pp. 51-62. Para su contexto familiar, véase BARCELó Crespí, Maria, Coll Tomàs, Baltasar y Rosselló Bordoy, Guillem: Espanyols i Pacs. Poder i cultura a la Mallorca del segle XV. Palma, Universitat de les Illes Balears, 1999.

111. Sobre la denominación del protagonista de la obra y, por extensión, de la misma, véase Romeu i Figueras, Josep: Lectura de textos medievals i renaixentistes. Valencia-Barcelona, Institut Universitari de Filologia Valencia-Publicacions de I'Abadia de Montserrat, 1994, p. 23; BUTIÑÁ JIMÉNEZ, Júlia: «Sobre Blaquerna/Blanquerna/Blaquerena, el protagonista de l'obra de Llull», Randa, 58 (2007), pp. 24-27.

112. Barceló Crespí, Maria y EnSEnyat Pujol, Gabriel: Clergues il./ustrats... pp. 49-65, especialmente pp. 52 y 56 61. Ver, también, BARCELÓ CRESPÍ, Maria: «Gregori Genovard i Espanyol, entre el cercle de canonges humanistes», en Ripoll Perelló, Maria Isabel y Tortella, Margalida (coords.): Ramon Llull i el lul.lisme: pensament i llenguatge. Palma, Universitat de Barcelona, Universitat de les Illes Balears, 2012, pp. 137-160, y BARCELó CRESPí, Maria: «El testament de dos humanistes: Gabriel Mora i Gregori Genovard», Bolletí de la Societat Arqueològica Lul.liana, 58 (2002), pp. 281-29o.

113. BarCeló Crespí, Maria y EnSenyat Pujol, Gabriel: Clergues il/lustrats... pp. 117-119. 


\section{LA MUERTE DE LOS REYES CATÓLICOS EN MALLORCA}

Un último ámbito de relación entre la Iglesia mallorquina y los soberanos era el funeral debido al producirse el óbito del monarca o de un pariente suyo. Así pues, al fallecer un miembro de la familia real, era costumbre realizar unas exequias en el patio del Castillo Real y, el día siguiente, otras en la catedral. Así se observó tras la muerte del rey Juan II de Aragón en I479, pero también después del fallecimiento del príncipe Juan en I497. Incluso Felipe el Hermoso, a pesar de no ser rey de Mallorca, contó con exequias pagadas por los jurados en $1506^{\mathrm{II}}$.

Como en todas las cuestiones en las que se veían involucradas varias instituciones, la organización de las exequias reales implicó siempre algún tipo de conflicto. Tras el óbito de la reina Isabel el 26 de noviembre de I504, se tuvieron que llevar a cabo los funerales pertinentes. Sin embargo, surgieron discrepancias entre la Iglesia de Mallorca y los jurados sobre cómo debían realizarse. Estas controversias condujeron a un bloqueo que se alargó durante un mes y medio. Al final, el I5 de enero de I505 el Cabildo designó a los canónigos Arnau de Santacília y Jaume Armadans para que llegaran a una concordia con los jurados sobre aquella cuestión ${ }^{15}$. La mediación fue un éxito, pues diez días más tarde, el 25 de enero, pudieron realizarse los funerales acostumbrados, primero en el patio de la Almudaina -pagados por el lugarteniente general-y, el día siguiente, en la catedral - a cargo de la Universidad ${ }^{\mathrm{II} 6}$.

La noche del 29 de enero de 1516 se recibió en Mallorca la noticia de que el rey Fernando el Católico había muerto en Madrigalejo el día 22 anterior, festividad de san Vicente mártir. La sesión capitular del día siguiente, en la que se informó del fallecimiento real, fue presidida por el vicario general, Guillem Grua, y contó con la asistencia del sacrista Nicolau Muntanyans, del precentor Llorenç de Santacília, y de los canónigos Antoni Joan Busquets, Joan Soldevila, Miquel Gual, Perot Pons, Joan Andreu Bibiloni, Gregori Genovard, Pere Aixartell, Francesc Net, Antoni Abelló, Llorenç Abrines y Arnau Albertí. Como fidelissimi vasalli que se consideraban, los canónigos determinaron que se procediera a hacer tocar todas las campanas de las iglesias de la ciudad para anunciar la noticia y rezar para la salvación del alma del monarca. Entre otras señales de duelo, también se dispuso que los menestrales tuvieran que trabajar con las puertas cerradas durante tres días, y se mandó que los canónigos y todos los eclesiásticos de la ciudad celebraran misa conventual en la catedral ${ }^{\mathrm{II}}$. Por otro lado, se organizaron las pertinentes exequias

114. Campaner Fuertes, Álvaro: op. cit. pp. 186, 196 y 221, respectivamente.

115. ACM, Actas Capitulares, 01-10-ACA-018, f. 62v.

116. Campaner Fuertes, Álvaro: op. cit. p. 220. Al fallecer Juan II, se realizaron tres funerales: en la Almudaina -pagado por el procurador real-, en la catedral -sufragado por la Universidad-y un tercero en la catedral -a expensas del obispo y del Cabildo-. SANTAMARÍA ArÁndeZ, Álvaro: «Mallorca, al advenir Fernando...» p. 20.

117. ACM, Actas Capitulares, 01-10-ACA-019, f. 229 r. 
reales -tanto en el patio de la Almudaina como en la catedral ${ }^{118}$-, juntamente al procurador real y a la Universidad de Mallorca; los gastos de los funerales fueron repartidos entre los distintos organizadores ${ }^{\mathrm{II}}$. Sin duda, en la catedral se edificó un monumento funerario, pues los canónigos abonaron diez sueldos a un pintor per pintar la tomba per las exequias del Rey ${ }^{\mathrm{I20}}$.

\section{CONCLUSIONES}

En las páginas anteriores se ha puesto de manifiesto la relación existente entre el rey Fernando Il y el Cabildo catedralicio de Mallorca. Como se ha indicado ya en el principio del presente artículo, la institución canonical mallorquina no era de las más importantes de la Monarquía Hispánica, de modo que su contacto con el rey era menor que el que pudieran tener los cabildos de las grandes seos hispanas. Pero esto no implica que el Cabildo de Mallorca no mantuviera una cierta relación con la monarquía, de modo que tampoco hay que menospreciar las constantes embajadas remitidas a la corte o el envío de correspondencia que se producía en ambas direcciones. Sí que hay que remarcar el papel del lugarteniente general, que, con frecuencia, ejercía un papel de intermediario entre los canónigos y el monarca, sin perjuicio, pero, que esos procedieran al envío de las susodichas embajadas. A tal efecto, se designaban uno o varios representantes, generalmente de entre los mismos canónigos. La idoneidad de los prebendados para el ejercicio de la representación era conocida, tal y como demuestra el hecho que el canónigo Genovard fuera designado embajador por los jurados en 15I5.

Esta prerrogativa de poder enviar embajadas al monarca no parece que fuera limitada, como sí sucedió a los jurados a partir de la segunda mitad del siglo $\mathrm{XVI}^{\mathrm{I21}}$. De hecho, el papel de las representaciones era fundamental, sobre todo si se tiene en cuenta que era la única forma de comunicarse con el rey y de defender directamente los intereses del Cabildo. Sin embargo, no sería una forma demasiado efectiva en el caso de los enfrentamientos con los obispos, pues la práctica totalidad de los prelados que se sucedieron entre I479 y I5I6 fueron designados por Fernando Il haciendo uso del derecho de súplica, y siempre recayeron en personas muy cercanas al monarca. Esto, además de ser la causa de la ausencia del mitrado mallorquín, también provocaría una entente entre el obispo y el rey, de

118. Campaner Fuertes, Álvaro: op. cit. p. 224. Aunque no se haya encontrado evidencia documental, seguramente el rey Fernando II también contó con las exequias tributadas por el clero mallorquín.

119. Los Jurados de Mallorca abonaron nueve libras. ACM, Actas Capitulares, 01-10-ACA-019, f. 236v.

120. ACM, Actas Capitulares, 2812, f. 6ov. La construcción de un monumento funerario -denominado tomba por extensión del ataúd que se colocaba- está muy bien documentada en Cataluña desde el siglo XIV. SABATÉ i CURULL, Flocel: Lo senyor rei és mort! Actitud i cerimònies del municipis catalans baix-medievals davant la mort del monarca. Lérida, Edicions de la Universitat de Lleida, 1994, pp. 85-100.

121. Planas Rosselló, Antonio: op. cit. pp. 66-67. 
modo que ambos se apoyarían mutuamente. El Cabildo, pues, tenía que defender sus intereses sin contar con el prelado en el caso de que el motivo de la queja tuviera relación con el monarca. A pesar de ello, no parece que Fernando Il fuera especialmente beligerante con el Cabildo y, de hecho, las relaciones tendieron a ser cordiales, aunque tampoco estuvieron exentas de tensiones: un caso ejemplar fue la gestión del interdicto al lugarteniente general en 1504.

Otro motivo de tensión entre la Corona y el Cabildo fue el Tribunal del Santo Oficio. El establecimiento de la Inquisición en Mallorca fue impuesto a pesar del rechazo de las autoridades del Reino. El Cabildo, a causa de la obediencia debida al rey y al papa, se prestó a colaborar con la nueva institución en lo que fuera necesario. Sin embargo, no fue tan favorable en el momento de conceder las rentas de una canonjía al inquisidor. De hecho, el rey Fernando Il tuvo que escribir personalmente al Cabildo para que se proveyera la prebenda, aunque sin éxito. Esto no implica, necesariamente, que los canónigos de Mallorca se opusieran a la Inquisición, sino que solo se negaban a desprenderse de un canonicato que les podía ser de interés para proveerlo a la persona que les fuera más conveniente.

La Iglesia de Mallorca también tuvo que colaborar, de una forma u otra, con las campañas bélicas promovidas por el rey Fernando II $^{122}$. En primer lugar, con la empresa conquistadora de Granada, mediante la cesión del diezmo concedido por Inocencio VIII en I487 o con la predicación de la bula de Cruzada. Aunque, sin duda, su participación más destacada fue en la conquista de Bugía de I5IO, fácilmente explicable por el interés de Mallorca en pacificar sus siempre atacadas costas. Es muy significativo el envío de toda una serie de objetos litúrgicos para contribuir en la recristianización de la diócesis africana, sobre todo atendiendo a que el obispo de aquella nueva plaza conquistada fue un mallorquín, Miquel Morro. También hay que destacar que aquella cesión fuera temporal, de modo que el prelado de Bugía se obligó a devolver todos los bienes, seguramente a medida que los fuera adquiriendo para el ornato de su nuevo obispado. Por otro lado, la catedral de Mallorca también participaba en los eventos de la Iglesia universal, como pudieran ser los distintos jubileos que se convocaron ${ }^{\mathrm{I23}}$.

En definitiva, el Cabildo catedralicio de Mallorca en el tránsito a la Modernidad era una institución que contaba con miembros muy capaces a nivel formativo y con preocupaciones para los temas de la Iglesia. Los canónigos supieron actuar con una única voz a la hora de defender las libertades e inmunidades de la lglesia de Mallorca, y no dudaron en enfrentarse al obispo, al rey o a sus representantes en el reino. Sin embargo, el respeto y la obediencia para con el monarca tendieron a marcar el comportamiento de los capitulares, que, en caso de discrepancia, siempre consideraron que Fernando Il había sido mal informado, por lo que

122. Fernando el Católico protagonizó una política exterior ambiciosa y expansionista, y la unión dinástica con Castilla le permitió acceder a numerosos recursos para llevarla a cabo. CASASNOVAS CAMPS, Miquel Àngel: op. cit. p. 218.

123. ACM, Actas Capitulares, 01-10-ACA-018, f. 3v y ACM, Actas Capitulares, 01-10-ACA-019, f. 133v. 
nunca fue culpado. Esta consideración puede hallarse también en la realización de exequias en sufragio de todos los miembros de la familia real, incluso para Felipe el Hermoso, cuya única vinculación con Mallorca fue la de ser el yerno del rey -a diferencia de Castilla, donde era esposo de la reina-. Por tanto, las reformas y medidas religiosas emprendidas por los Reyes Católicos en lo que refiere a la Iglesia pudieron implementarse sin demasiadas dificultades al encontrarse con un Cabildo complaciente, aunque vigilante. La frecuente remisión de embajadas a la corte para explicarse ante el rey es una prueba de su voluntad de obedecer, aunque sin renunciar, en ningún caso, a los derechos que hubieran podido adquirir a lo largo de más de doscientos años de historia. 


\section{BIBLIOGRAFÍA}

Alonso Acero, Beatriz: Cisneros y la conquista española del norte de África: cruzada, política $y$ arte de la guerra. Madrid, Ministerio de Defensa, 2005.

ANDrÉs Martín, Melquíades: «La espiritualidad franciscana en España en tiempos de las observancias (I380-I5I7)», Studia Historica. Historia Moderna, 6 (I988), pp. 465-479.

AzNAR VALLEjo, Eduardo: «Los inicios de la bula de Cruzada en Canarias», Revista Española de Derecho Canónico, 44/122 (1987), pp. 205-219.

BARBERI, Josep: Vida de la venerable madre sor Clara Andreu, natural de Palma, capital del Reyno de Mallorca, religiosa gerónima en el monasterio de San Bartolomé de la villa de Inca, con un apéndice histórico de dicha villa. Palma, Imprenta de Melchor Guasp, I807.

Barceló Crespí, Maria: «Conflicto entre los jurados y el obispo y Cabildo de Mallorca (I478)», Anuario de Estudios Medievales, 29 (1999), pp. 2I-33.

BARCEló Crespí, Maria: «Agnès de Pacs i l'entorn humanista», Memòries de la Reial Acadèmia Mallorquina d'Estudis Genealògics, Heràldics i Històrics, Io (2000), pp. 2I-47.

BARCEló Crespí, Maria: «El testament de dos humanistes: Gabriel Mora i Gregori Genovard», Bolletí de la Societat Arqueològica Lulliana, 58 (2002), pp. 28I-290.

Barceló Crespí, Maria: «Gregori Genovard i Espanyol, entre el cercle de canonges humanistes», en Ripoll Perelló, Maria Isabel y Tortella, Margalida (coords.): Ramon Llull i el lul.lisme: pensament i llenguatge. Palma, Universitat de Barcelona, Universitat de les Illes Balears, 2012, pp. I37-I60.

Barceló Crespí, Maria, Coll Tomàs, Baltasar y Rosselló Bordoy, Guillem: Espanyols $i$ Pacs. Poder i cultura a la Mallorca del segle XV. Palma, Universitat de les Illes Balears, I999.

Barceló Crespí, Maria y Ensenyat Pujol, Gabriel: Els nous horitzons culturals a Mallorca al final de l'Edat Mitjana. Palma, Documenta Balear, 2000.

Barceló Crespí, Maria y EnSenyat Pujol, Gabriel: «Esperandeu Espanyol, un canonge del segle XV amb interessos humanistes i lul-listes», Bolletí de la Societat Arqueològica Lul.liana, 66 (2010), pp. 5I-62.

Barceló Crespí, Maria y EnSenyat Pujol, Gabriel: Clergues il.lustrats. Un cercle humanista a l'entorn de la Seu de Mallorca (I450-I550). Palma, Publicacions Catedral de Mallorca, 2013.

Barceló Crespí, Maria y Urgell Hernández, Ricard: «La Universitat de Mallorca: origen i evolució fins el segle XVIII», en BusQueta i Riu, Joan J. y Pemán Gavín, Juan (coords.): Les universitats de la Corona d'Aragó, ahir i avui. Estudis històrics. Barcelona, Pòrtic, 2002, pp. I57-I92.

Belenguer Cebrià, Ernest: Jaume I a través de la historia. Valencia, Publicacions de la Universitat de València, 2009.

BELlo León, Juan Manuel: «Apuntes para el estudio de la influencia del corso y la piratería en la política exterior de los Reyes Católicos», Historia. Instituciones. Documentos, 23 (I996), pp. 77-84.

Butiñá JIMÉNEZ, Júlia: «Sobre Blaquerna/Blanquerna/Blaquerena, el protagonista de l'obra de Llull», Randa, 58 (2007), pp. 23-37.

Campaner Fuertes, Âlvaro: Cronicón Mayoricense. Palma, I967.

Cantera Montenegro, Margarita: «Las órdenes religiosas», Medievalismo, I3-I4 (2004), pp. II3-I26.

Casasnovas Camps, Miquel Àngel: Història de les Illes Balears. Palma, Editorial Moll, I998. 
CASSANYES RoIG, Albert: «El Capítol catedralici de Ramon Llull (I232-I316)», en FullanA Puigserver, Pere y Gambús Saiz, Mercè (coords.): Ramon Llull i la Seu de Mallorca. Palma, Publicacions Catedral de Mallorca, 20i6, pp. 43-77.

CASSANYES Roig, Albert: «La provisión de canonicatos y obispados en Mallorca durante el reinado de Fernando Il el Católico (I479-I5I6)», en trámite de publicación.

CASSANYES Roig, Albert y RAmis BARCELÓ, Rafael: «Fray Junípero Serra y la Universidad Luliana y Literaria de Mallorca», Archivum Franciscanum Historicum, IO7 (20I4), pp. 427-456.

CAssanyes Roig, Albert y Ramis Barceló, Rafael: «Los grados en Teología escotista en la Universidad Luliana y Literaria de Mallorca (I692-I823)», Archivo Ibero-Americano, 74/277-278 (2014), pp. 7-5I.

Cateura BennÀsser, Pau: L'administració atrapada. Crèdit, finances i adaptacions fiscals en el Regne de Mallorca (segle XV). Palma, El Tall, 2008.

Colom Palmer, Mateu: La Inquisició a Mallorca (I488-1578). Barcelona, Curial, 1992.

CORTÈs i Cortès, Gabriel: Historia de los judíos mallorquines y de sus descendientes cristianos. Palma, Miquel Font, editor, I985.

Dameto, Joan, Mut, Vicenç y Alemany, Jeroni: Historia General del Reino de Mallorca. Palma, Imprenta Nacional á cargo de D. Juan Guasp y Pascual, I84I.

Deyà BauzÀ, Miquel Josep: «Entre la toma de Orán y los pactos con Argel: las Baleares y la conquista de Bugía», en Bunes Ibarra, Miguel Ángel de y Alonso Acero, Beatriz (coords.): Orán. Historia de la corte chica. Madrid, Polifemo, 20II, pp. 55-82.

Dumont, Jean: La «incomparable» Isabel la Católica. Madrid, Encuentro, 1993.

EDWARDS, John: La España de los Reyes Católicos. Madrid, Crítica, 200I.

Ensenyat Pujol, Gabriel: «Les institucions d'alta cultura: de l'Estudi General Lul.lià a la Universitat Literària», en Bonner, Anthony y Bujosa Homar, Francesc (dirs.): Història de la Ciència a les Illes Balears. Volum II. El Renaixement. Palma, Conselleria d'Economia, Hisenda i Innovació, 2006, pp. 17-33.

Escudero López, José Antonio: «Los Reyes Católicos y el establecimiento de la Inquisición», Anuario de Estudios Atlánticos, 50/I (2004), pp. 386-393.

Fernández Álvarez, Manuel: Isabel la Católica. Madrid, Espasa Calpe, 2003.

Fita Colomé, Fidel: «Nuevas fuentes para escribir la historia de los judíos españoles: bulas inéditas de Sixto IV e Inocencio VIII», Boletín de la Real Academia de la Historia, I5 (I889), pp. 447-458.

Furió SASTRE, Antonio: Vida del bendito padre fray Bartolomé Catany. Palma, Imprenta a cargo de D. Juan Guasp, I85I.

Furió SASTRE, Antonio: Episcopologio de la Santa Iglesia de Mallorca. Palma, Juan Guasp, I852.

Galende Díaz, Juan Carlos y Cabezas Fontanilla, Susana: «Historia y documentación del Santo Oficio español: el periodo fundacional», III Jornadas Científicas Sobre Documentación en época de los Reyes Católicos, Madrid, 2004, GAlende Díaz, Juan Carlos (dir.), Madrid, Universidad Complutense de Madrid, 2004, pp. II9-I45.

García de la Borbolla, Ángeles: «El culto y devoción del lignum crucis en los reinos occidentales de la península ibérica (VII-XV)», Pecia. Ressources en medievistique, 8/II (2005), pp. 565-600.

Garcías Palou, Sebastià: El Miramar de Ramon Llull. Palma, Institut d'Estudis Baleàrics, CSIC, 1977 .

HiLlgarTh, Jocelyn Nigel: «La cultura de las Islas Baleares en la época del descubrimiento», Congrés Internacional d'Estudis Històrics. Les Illes Balears i Amèrica. Volum I. Palma, gener, 1992, Piña Homs, Román (coord.), Palma, Institut d'Estudis Baleàrics, I992, pp. 39-46. IsaAcs, A. Lionel: Els jueus de Mallorca. Palma, Miquel Font, editor, I986. 
JUAN VIDAL, Josep: «Los diezmos en la diócesis de Mallorca en el siglo XVI», Mayurqa, 22 (I989), pp. 8II-824.

JUAN VIDAL, Josep: «Mallorca en la segunda mitad del siglo XV. Panorama socioeconómico», Medicina Balear, 22/extra I (2007), pp. 22-32.

Ladero Quesada, Miguel Ángel: La Guerra de Granada (I482-I49I). Granada, Diputación Provincial de Granada, 200I.

Llabrés Quintana, Gabriel: «Testamento de doña Beatriz de Pinós», Bolletí de la Societat Arqueològica Lul.liana, 20 (I925), pp. 305-310.

Lladó i FerRagut, Jaume: Historia del Estudio General Luliano y de la Real y Pontificia Universidad Literaria de Mallorca. Palma, Ediciones Cort, I973.

Lladonosa i Pujol, Josep: Relacions entre Mallorca i Lleida a l'època medieval. Barcelona, Rafael Dalmau, Editor, I976.

Lop Oтín, María José: El cabildo catedralicio de Toledo en el siglo XV: aspectos institucionales y sociológicos (tesis doctoral inédita), Universidad Complutense de Madrid, 200 I.

Marcu, Valeriu: La expulsión de los judíos de España. Sevilla, Renacimiento, 2002.

Mateu Mairata, Gabriel: Obispos de Mallorca. Palma, Ediciones Cort, 1985.

PÉrez, Joseph: Isabel y Fernando. Los Reyes Católicos. Madrid, Nerea, 200I.

PÉrez, Joseph: Historia de una tragedia. La expulsión de los judíos de España. Barcelona, Crítica, 2009.

Pérez Martínez, Lorenzo: «El maestro Daguí y el lulismo mallorquín de fines del siglo $\mathrm{XV} »$, Estudios Lulianos, I2 (I960), pp. 29I-306.

Pérez Martínez, Lorenzo (ed.): Reivindicación de los judios mallorquines. Documentos para su estudio, I. Palma, I983.

Planas Rosselló, Antonio: Los jurados de la Ciudad y Reino de Mallorca (I249-I718). Palma, Lleonard Muntaner, editor, 2005.

RAMIS BARCELó, Rafael: «Sobre la denominación histórica de la universidad de Mallorca», Cuadernos del Instituto Antonio de Nebrija, I3/2 (2010), pp. 237-263.

RAMIS BARCELÓ, Rafael: «Un esbozo cartográfico del lulismo universitario y escolar en los reinos hispánicos», Cuadernos del Instituto Antonio de Nebrija, I5/I (2012), pp. 6I-I03.

RAmis Barceló, Rafael: «En torno al escoto-lulismo de Pere Daguí», Medievalia, I6 (2013), pp. 235-264.

RAMIS BARCELó, Rafael: «Peregrinatio academica: legistas y canonistas de la Corona de Aragón en las universidades italianas durante el Renacimiento», Miscellanea Historico-iuridica, I3/I (2014), pp. 35-66.

RAPP, Francis: La Iglesia y la vida religiosa en Occidente a fines de la Edad Media. Barcelona, Labor, I973.

Rey, Eusebio: «La bula de Alejandro VI otorgando el título de 'Católicos' a Fernando e Isabel», Razón y Fe, I46 (I952), pp. 59-75.

Rojo AlıQue, Francisco Javier: «Reforma religiosa, sociedad y política en la Baja Edad Media: el ejemplo de San Francisco de Palencia en el siglo XV», Hispania Sacra, LIX/I20 (2007), pp. 469-49I.

Romeu i Figueras, Josep: Lectura de textos medievals i renaixentistes. Valencia-Barcelona, Institut Universitari de Filologia Valencia-Publicacions de l'Abadia de Montserrat, I994.

Sabaté i Curull, Flocel: Lo senyor rei és mort! Actitud i cerimònies del municipis catalans baix-medievals davant la mort del monarca. Lérida, Edicions de la Universitat de Lleida, I994.

SAn Miguel Pérez, Enrique: Isabel I de Castilla. I474-I504. Burgos, La Olmeda, I998. 
SANTAMARía ArÁndez, Álvaro: «Mallorca, al advenir Fernando el Católico», Mayurqa, 2 (I969), pp. I9-47.

SANTAMARÍA ARÁNDEZ, Álvaro: «Pragmática de Granada, una década de la historia de Mallorca (I495-I504)», Boletín de la Cámara Oficial de Comercio, Industria y Navegación de Palma de Mallorca, 670-67I (I97I), pp. 3-73.

Santamaría ArÁndez, Álvaro: «La donación proluliana de Beatriu de Pinós», Bolletí de la Societat Arqueològica Lul.liana, 35 (I976), pp. 37-I40.

SANTAMARía ARÁndez, Álvaro: La promoción universitaria en Mallorca. Época de Fernando el Católico (I479-I5I6). Palma, Universitat de Palma de Mallorca, I983.

SANTAMARía ARÁNDEZ, Álvaro: «Sobre la condición de los conversos y chuetas de Mallorca», Espacio, tiempo y forma. Serie III, Historia Medieval, io (I997), pp. 219-26I.

Serrano Rodríguez, Eugenio y Gómez Vozmediano, Miguel Fernando: «Imprenta, dinero y fe: la impresión de bulas en el convento dominico de San Pedro Mártir de Toledo (I483-I60o)», Tiempos Modernos, 7/27 (2013): http://tiemposmodernos.org/tm3/index.php/ tm/article/viewFile/347/392 [consultado el 2 de enero de 2017].

SuÁrez Fernández, Luis: Los Reyes Católicos. La conquista del trono. Madrid, Rialp, I989.

SUÁREZ FERnÁNDEZ, Luis: La expulsión de los judíos. Un problema europeo. Barcelona, Ariel, 2012.

Trias Mercant, Sebastià: Història del pensament a Mallorca. Volum I. Del orígens al segle XIX. Palma, Editorial Moll, I985.

Urgell Hernández, Ricard: «Dinàmica del deute públic a la Universitat de Mallorca en el segle XV», en Sánchez Martínez, Manuel, Furió i Diego, Antoni y Bertran i Roigé, Prim (coords.). Colloqui Corona, municipis i fiscalitat a la Baixa Edat Mitjana. Lérida, Institut d'Estudis Ilerdencs, I997, pp. 675-70I.

VAL VAldivieso, María Isabel del: «Isabel la Católica. Una mujer para el trono de Castilla», Memòries de la Reial Acadèmia Mallorquina d'Estudis Genealògics, Heràldics i Històrics, I4 (2004), pp. 7-23.

Vargas Martínez, Ana: «Beatriu de Pinós y Agnès de Pacs: el origen femenino de las escuelas lulianas en la Mallorca del siglo XV», en Díaz SÁnchez, Pilar, Franco Rubio, Gloria y Fuentes Pérez, María Jesús (eds.): Impulsando la historia desde la historia de las mujeres. Huelva, Universidad de Huelva, 20I2, pp. 409-4I5.

Villanueva, Jaime: Viage literario a las iglesias de España. Tomo XXII. Viage á Mallorca. Madrid, Imprenta de la Real Academia de la Historia, I852.

VV.AA.: Actas del II Congreso Internacional de Lulismo. Palma, Maioricensis Schola Lullistica, 1979, 3 vols.

VV.AA.: Historia de Marruecos. Madrid, Consejería de Educación y Ciencia, Embajada de España en Marruecos, 1996. 
Calidad de Revistas

Científicas Españolas

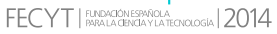

AÑO 2017

ISSN: 0214-9745

E-ISSN 2340-1362

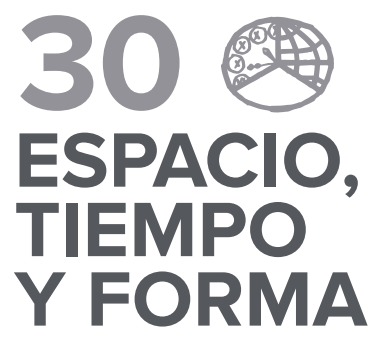

SERIE III HISTORIA MEDIEVAL

REVISTA DE LA FACULTAD DE GEOGRAFİA E HISTORIA

\section{Artículos · Articles}

15 Vicente Ángel Álvarez Palenzuela

Del gobierno de la oligarquía a la tiranía de D. Álvaro (1435-1439). From the Government of the Oligarchy to the Tyranny of Don Álvaro (1435-1439)

83 Carlos Barquero GoÑ

Hospitalarios y obispos en Castilla durante los siglos XII y XIII Hospitallers and Bishops in Castile during the Twelfth and Thirteenth Centuries

Gonzalo Carrasco García

Ritual político, antropología e historiografía bajomedieva hispánica P Political Ritual, Anthropology and Scholarship on Late Medieval Spain

\section{Albert Cassanyes Roig}

El cabildo catedralicio de Mallorca y la política de Fernando II el Católico. The Cathedral Chapter of Majorca and the Politics of Fernando II the Catholic

\section{ELISA CASELL}

El antijudaísmo en la administración de justicia ordinaria. E caso de un corregidor castellano de finales del siglo XV · Anti-Judaism in the Administration of Justice. The Case of a Castilian Magistrate in the Late Fifteenth Century

\subsection{MÁxIMO DIAGO HERnANDO}

Violencia en las actuaciones políticas del clero catedralicio en Plasencia a fines del siglo XV y comienzos del XVI - Violence in the Politica Action of the Cathedral Clergy of Plasencia in the Latter Fifteenth and Early Sixteenth Centuries

\section{MARISOL ENCINAS MANCHADO}

La inscripción medieval de la estela romana de Dombellas (Soria): su razonable relación con la leyenda de Muño Sancho de Finojosa - The Medieval Inscription on the Roman Stele found in Dombellas (Soria) and its Probable Relation to the Legend of Muño Sancho de Finojosa

309 María jesús Fuente

Más allá del amor: mujeres moras y judías víctimas de violencia en la Castilla del siglo XV . Beyond Love: Muslim and Jewish Women Victims of Violence in Fifteenth-Century Castile

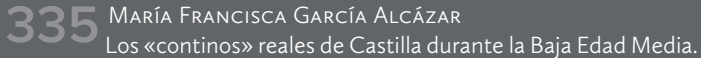
Estado de la cuestión. Royal Continos in Castile during the Late Middle Ages. A State of the Question

359 María Dolores García Oliva

Conflictos en torno a las tierras comunales en el término de Plasencia hacia finales de la Edad Media . Conflicts Concerning the Communal Lands of Plasencia at the End of the Middle Ages

387 SANTIAGO GONZÁLEZ SÁnCHEZ

Las Cortes durante la minoría de Juan II de Castilla · The Cortes during the Minority of Juan II of Castile

455 Francisco Marmolejo Cantos

Movimientos migratorios en el reino de Granada. El caso de La Torrecilla, despoblado del alfoz de Coín (Málaga) - Migratory Movements in the Kingdom of Granada. The Case of La Torrecilla, a Deserted Settlement in the Hinterland of Coín (Málaga)

4.85 Ángel Rozas EsPañol

La ruta atlántica (siglos XIII-XIV): análisis de la formación de una ruta comercial . The Atlantic Route (Thirteenth and Fourteenth Centuries): Analysis of the Development of a Trade Route

505 Juan José Sánchez Carrasco

Las dos dotaciones fundacionales del monasterio de Santa María de la Concepción de Granada. The Two Founding Endowments of the Monastery of Santa María de la Concepción of Granada

539 Josué VilLa PRIETo

Cronística y nobleza en la Italia bajomedieval: la Casa de Este (Ferrara-Módena-Reggio) · Chronicles and Nobility in Italy during the Late Middle Ages: The House of Este (Ferrara-Modena-Reggio)

\section{Evocación · Evocation}

575 Francisco Abad Nebot

Joan Reglà (27 de Julio de 1917- 27 de Diciembre de 1973) y el medievalismo - Joan Reglà (27 of July, 1917 - 27 of December, 1973) and Medievalism 


\section{0}

\section{ESPACIO,}

\section{TIEMPO}

Y FORMA

UกED

SERIE III HISTORIA MEDIEVAL

REVISTA DE LA FACULTAD DE GEOGRAFÍA E HISTORIA

\section{Libros · Books}

583 Aguiar Andrade, Amélia, Millán da Costa, Adelaide (eds.), La ville médiévale en débat (ANA María Rivera Medina)

591 CASELLI, Elisa, Antijudaïme, pouvoir politique et administration de la justice. Juifs, chrétiens et converts dans I' espace jurisdictionnel de la Chancillería de Valladolid (XVé-XVle siècles) (ENRIQUE CANTERA MONTENEGRO)

595 GonzÁlez Mínguez, César, A vueltas con la crisis bajomedieval. El entorno Cantera Montenegro) económico del reinado de Fernando IV de Castilla (1295-1312) (ENRIQUE

601 JuncosA BONET, Eduard, Estructura y dinámicas de poder en el señorío de Tarragona. Creación y evolución de un dominio compartido (ca. 1118-1462) (RAFAel NaRbona VizCAínO)

607 Peel, Christine (trad.), Guta Lag. The Law of the Gotlanders (José Miguel García Pimentel

611 Rodríguez WitTMAn, Kevin, Las islas del fin del mundo. Representación de ZALACAIN)

las afortunadas en los mapas del occidente medieval (ROBERTO J. GONZÁLEZ

615 Torres Jiménez, Raquel y Ruiz Gómez, Francisco (eds.), Órdenes militares y construcción de la sociedad occidental (siglos XII-XV) (JOsÉ Manuel Rodríguez García)

619 Zapatero, MARIANA, Alimentación y abastecimiento de carne. El caso castellano durante la Baja Edad Media: mercado, consumo y cultura (ANA María Rivera Medina) 